\title{
Complete mitochondrial genomes confirm the distinctiveness of the horse-dog and sheep-dog strains of Echinococcus granulosus
}

\author{
T. H. LE ${ }^{1}$, M. S. PEARSON ${ }^{1}$, D. BLAIR ${ }^{2}$, N. DAI ${ }^{1}$, L. H. ZHANG ${ }^{1}$ and D. P. MCMANUS ${ }^{1 *}$ \\ ${ }^{1}$ Molecular Parasitology Laboratory, Australian Centre for International and Tropical Health and Nutrition, The \\ Queensland Institute of Medical Research and The University of Queensland, Brisbane, Queensland 4029, Australia \\ ${ }^{2}$ School of Tropical Biology, Fames Cook University, Townsville, Queensland 4811, Australia
}

(Received 23 Fune 2001; revised 9 August 2001; accepted 9 August 2001)

S UM M A R Y

Unlike other members of the genus, Echinococcus granulosus is known to exhibit considerable levels of variation in biology, physiology and molecular genetics. Indeed, some of the taxa regarded as 'genotypes' within E. granulosus might be sufficiently distinct as to merit specific status. Here, complete mitochondrial genomes are presented of 2 genotypes of $E$. granulosus (G1-sheep-dog strain: G4-horse-dog strain) and of another taeniid cestode, Taenia crassiceps. These genomes are characterized and compared with those of Echinococcus multilocularis and Hymenolepis diminuta. Genomes of all the species are very similar in structure, length and base-composition. Pairwise comparisons of concatenated protein-coding genes indicate that the G1 and G4 genotypes of E. granulosus are almost as distant from each other as each is from a distinct species, E. multilocularis. Sequences for the variable genes atp6 and nad3 were obtained from additional genotypes of $E$. granulosus, from E. vogeli and E. oligarthrus. Again, pairwise comparisons showed the distinctiveness of the G1 and G4 genotypes. Phylogenetic analyses of concatenated atp6, nad1 (partial) and cox1 (partial) genes from E. multilocularis, E. vogeli, E. oligarthrus, 5 genotypes of E. granulosus, and using T. crassiceps as an outgroup, yielded the same results. We conclude that the sheep-dog and horse-dog strains of E. granulosus should be regarded as distinct at the specific level.

Key words: Echinococcus granulosus, mitochondrial genome, mitochondrial DNA, strain, genotype; horse-dog strain, sheep-dog strain, phylogeny.

\section{INTRODUCTION}

Only 4 of the 16 nominal Echinococcus species are generally accepted as being taxonomically validEchinococcus granulosus, E. multilocularis, E. vogeli and E. oligarthrus. All the other taxa are regarded as subspecific variants or strains of $E$. granulosus (Thompson \& McManus, 2001). These conclusions were based on differences in morphologies of adult worms, host ranges, life-cycle patterns, the nature and location of the hydatid cyst, and biochemical and molecular characteristics (Thompson \& McManus, 2001). It is now increasingly clear that the nearcosmopolitan E. granulosus exhibits considerable variation at the genetic level and that a re-evaluation of its taxonomy is merited. Indeed, based on a range of different biological, epidemiological, biochemical and molecular-genetic criteria, separate species status for the horse-dog (G4 genotype) and sheep-

* Corresponding author: Molecular Parasitology Laboratory, Australian Centre for International and Tropical Health and Nutrition, The Queensland Institute of Medical Research and The University of Queensland, Brisbane, Queensland 4029, Australia. Tel: +61 73362 0401.Fax:+61 73362 0104.E-mail:donM@qimr.edu.au dog (G1 genotype) strains has been advocated (Bowles, Blair \& McManus, 1995; Thompson, 1995; Thompson, Lymbery \& Constantine, 1995). The extensive intra-specific variation in nominal $E$. granulosus must impact on the epidemiology, pathology and control of hydatid disease (Thompson \& Lymbery, 1988; Thompson, 1995), with important implications also for the design and development of vaccines, diagnostic reagents and drugs. By contrast, there appears to be very limited genetic variation within E. multilocularis (McManus \& Bryant, 1995; Haag et al. 1997; Rinder et al. 1997), and there are no available data to indicate that either $E$. vogeli or $E$. oligarthrus is variable.

Mitochondrial ( $\mathrm{mt}$ ) sequences provide rich sources of data for research in evolutionary biology, population genetics and phylogenetics and are increasingly being used in studies of the genus Echinococcus (see Le, Blair \& McManus, 2000a). To date, molecular studies, using mainly mtDNA sequences, have identified 9 distinct genotypes within $E$. granulosus (Bowles, Blair \& McManus, 1992, 1994; Bowles \& McManus, $1993 a, b$; Scott \& McManus, 1994; Scott et al. 1997). Nonetheless, there is still a paucity of information regarding the structure and characteristics of the mt genomes of this and other 


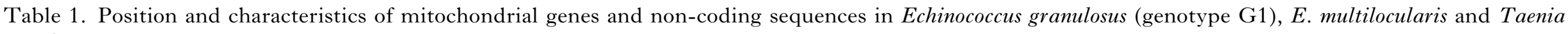
crassiceps

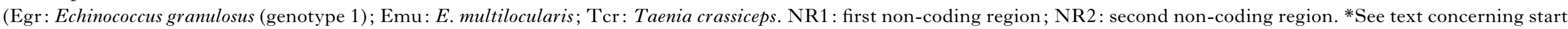
and stop codons for $\operatorname{cox} 1$ and the length of $\operatorname{trn} T$. The sequence tract indicated here for trnT forms a tRNA lacking a paired DHU arm (see text).)

\begin{tabular}{|c|c|c|c|c|c|c|c|c|c|c|c|c|c|c|c|}
\hline \multirow[b]{3}{*}{ Gene and sequence } & \multicolumn{6}{|c|}{ Length of genes and sequences } & \multicolumn{6}{|c|}{ Codon used for } & \multirow{2}{*}{\multicolumn{3}{|c|}{$\frac{\text { Position }}{\left(5^{\prime} \rightarrow 3^{\prime}\right)}$}} \\
\hline & \multicolumn{3}{|c|}{ Nucleotide } & \multicolumn{3}{|c|}{ Amino acid } & \multicolumn{3}{|c|}{ Initiation } & \multicolumn{3}{|c|}{ Termination } & & & \\
\hline & Egr & Emu & Tcr & Egr & Emu & Tcr & Egr & Emu & Tcr & Egr & Emu & Tcr & Egr & Emu & Tcr \\
\hline $\cos 3$ & 648 & 648 & 645 & 215 & 215 & 214 & ATG & ATG & GTG & TAG & TAG & TAG & $1-648$ & $1-648$ & $1-645$ \\
\hline $\operatorname{trn} H$ & 65 & 68 & 71 & & & & & & & & & & $649-713$ & $650-717$ & $646-716$ \\
\hline$c o b$ & 1068 & 1068 & 1074 & 355 & 355 & 357 & ATG & ATG & ATG & TAA & TAA & TAA & $717-1784$ & $720-1787$ & $720-1793$ \\
\hline $\operatorname{nad} 4 L$ & 261 & 261 & 261 & 86 & 86 & 86 & GTG & GTG & ATG & TAA & TAG & TAG & $1798-2058$ & $1798-2058$ & $1793-2053$ \\
\hline nad4 & 1260 & 1260 & 1260 & 419 & 419 & 419 & ATG & ATG & GTG & TAG & TAG & TAG & 2019-3278 & 2019-3278 & $2014-3273$ \\
\hline $\operatorname{trn} Q$ & 62 & 61 & 63 & & & & & & & & & & $3282-3343$ & $3285-3345$ & $3279-3345$ \\
\hline $\operatorname{trn} \widetilde{F}$ & 63 & 63 & 64 & & & & & & & & & & $3343-3405$ & $3345-3407$ & $3342-3405$ \\
\hline $\operatorname{trn} M$ & 66 & 65 & 67 & & & & & & & & & & $3402-3467$ & $3404-3468$ & $3402-3468$ \\
\hline atp6 & 513 & 516 & 513 & 170 & 171 & 170 & ATG & ATG & GTG & TAG & TAG & TAA & $3473-3985$ & 3747-3989 & 3469-3981 \\
\hline nad2 & 882 & 882 & 879 & 293 & 293 & 292 & ATG & ATG & ATG & TAG & TAG & TAG & $3994-4875$ & $3998-4879$ & $3981-4859$ \\
\hline $\operatorname{trn} V$ & 63 & 63 & 64 & & & & & & & & & & $4900-4962$ & $4902-4964$ & $4867-4930$ \\
\hline $\operatorname{trn} A$ & 64 & 64 & 64 & & & & & & & & & & $4968-5031$ & $4970-5033$ & $4935-4998$ \\
\hline $\operatorname{trn} D$ & 65 & 63 & 66 & & & & & & & & & & $5032-5096$ & $5034-5096$ & $5002-5067$ \\
\hline nad1 & 894 & 894 & 894 & 297 & 297 & 297 & GTG & ATG & ATG & TAA & TAG & TAG & $5100-5993$ & $5100-5993$ & 5075-5968 \\
\hline $\operatorname{trn} N$ & 66 & 66 & 67 & & & & & & & & & & $6010-6075$ & $6011-6076$ & 5971-6037 \\
\hline $\operatorname{trn} P$ & 63 & 63 & 66 & & & & & & & & & & $6082-6144$ & $6083-6145$ & $6053-6118$ \\
\hline $\operatorname{trnI}$ & 62 & 62 & 64 & & & & & & & & & & $6145-6206$ & $6146-6207$ & 6119-6182 \\
\hline $\operatorname{trnK}$ & 62 & 66 & 65 & & & & & & & & & & $6213-6274$ & $6214-6279$ & $6188-6252$ \\
\hline nad3 & 348 & 348 & 348 & 115 & 115 & 115 & ATG & ATG & GTG & TAG & TAA & TAG & $6277-6624$ & $6280-6627$ & $6255-6602$ \\
\hline $\operatorname{trn} S_{1(A G N)}$ & 59 & 59 & 59 & & & & & & & & & & $6623-6681$ & 6639-6697 & $6601-6659$ \\
\hline $\operatorname{trn} W^{1(A G N)}$ & 67 & 65 & 64 & & & & & & & & & & $6690-6756$ & $6706-6770$ & $6661-6724$ \\
\hline $\operatorname{cox} 1 *$ & 1581 & 1581 & 1596 & 526 & 526 & 531 & GTG & GTA & ATG & TAG & TAG & TAG & $6787-8367$ & $6801-8381$ & $6746-8341$ \\
\hline $\operatorname{trn} T^{*}$ & 55 & 55 & 58 & & & & & & & & & & $8367-8421$ & $8385-8439$ & $8337-8394$ \\
\hline $\operatorname{rrnL}(16 S)$ & 978 & 983 & 963 & & & & & & & & & & $8422-9399$ & $8441-9423$ & 8395-9357 \\
\hline $\operatorname{trn} C$ & 63 & 64 & 59 & & & & & & & & & & $9400-9462$ & $9424-9487$ & $9358-9416$ \\
\hline$r r n S(12 S)$ & 719 & 723 & 722 & & & & & & & & & & 9463-10181 & 9488-10210 & 9417-10138 \\
\hline $\cos 2$ & 582 & 582 & 585 & 193 & 193 & 194 & GTG & GTG & ATG & TAG & TAG & TAG & $10182-10763$ & $10211-10792$ & 10139-10723 \\
\hline $\operatorname{trn} E$ & 67 & 68 & 69 & & & & & & & & & & 10779-10845 & $10810-10877$ & $10725-10793$ \\
\hline nad6 & 456 & 456 & 453 & 151 & 151 & 150 & ATG & ATG & ATG & TAG & TAA & TAA & 10849-11304 & 10880-11335 & 10796-11248 \\
\hline $\operatorname{trn} Y$ & 66 & 66 & 69 & & & & & & & & & & $11316-11381$ & $11348-11413$ & $11256-11324$ \\
\hline NR1 & 66 & 183 & 65 & & & & & & & & & & $11382-11447$ & $11414-11596$ & 11325-11389 \\
\hline $\operatorname{trn} L_{1(C U N)}$ & 73 & 73 & 65 & & & & & & & & & & $11448-11520$ & 11597-11669 & 11390-11454 \\
\hline $\operatorname{trn} S_{2(U C N)}$ & 58 & 58 & 59 & & & & & & & & & & 11559-11616 & $11707-11764$ & $11480-11538$ \\
\hline $\operatorname{trn} L_{3(U U N)}^{2(U C N)}$ & 64 & 64 & 65 & & & & & & & & & & $11630-11693$ & $11778-11841$ & 11545-11609 \\
\hline $\operatorname{trnR}$ & 58 & 58 & 56 & & & & & & & & & & $11703-11760$ & 11857-11914 & $11617-11672$ \\
\hline nad5 & 1572 & 1575 & 1569 & 523 & 524 & 522 & ATG & ATG & ATG & TAG & TAA & TAA & 11763-13334 & $11916-13490$ & 11674-13242 \\
\hline NR2 & 184 & 177 & 194 & & & & & & & & & & $13335-13518$ & $13491-13667$ & $13243-13436$ \\
\hline $\operatorname{trn} G$ & 67 & 68 & 64 & & & & & & & & & & 13519-13585 & $13668-13735$ & $13437-13500$ \\
\hline
\end{tabular}

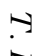




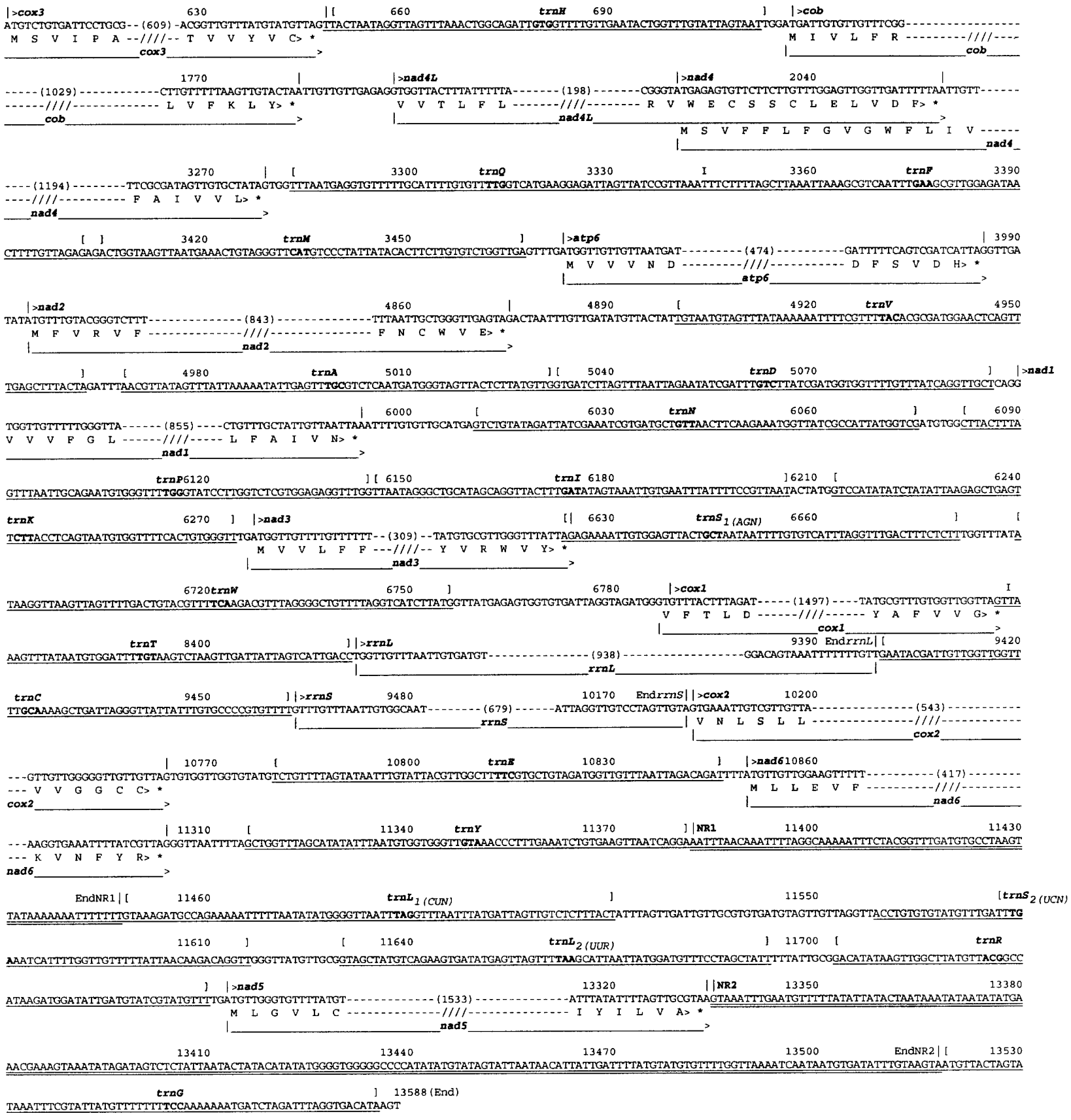

Fig. 1. Abbreviated mitochondrial sequence of Echinococcus granulosus (G1 genotype) showing gene arrangement (see text for details).

cestodes which has hindered efforts to further advance epidemiological and phylogenetic studies and to address taxonomic questions (McManus \& Bryant, 1995; Bowles et al. 1995; Le et al. 2000 a).

Here, we describe, characterize and compare the complete mt sequences for the common sheep (G1 genotype) and horse (G4 genotype) strains of $E$. granulosus relative to the $\mathrm{mt}$ sequence of $E$. multilocularis (M. Nakao, GeneBank Accession number AF018440) and another taeniid species, Taenia crassiceps (Le et al. 2000). These comparisons show that the G1 and G4 genotypes of E. granulosus are almost as distinct from each other as either is from $E$. multilocularis. Some comparisons have also been made with the recently published complete sequence of the mt genome of the more distantly related cyclophyllidean cestode, Hymenolepis diminuta (see von Nickisch-Rosenegk, Brown \& Boore, 2001). Additionally, a comparison of protein-encoding genes (atp6, nad1, nad3 and cox1) for a number of Echinococcus genotypes and species (E. granulosus genotypes G1, G4, G6, G7, G8; E. multilocularis; E. vogeli; E. oligathrus) is made for consideration of their genetic variation and phylogeny. 
Table 2. Nucleotide codon usage for mitochondrial protein-encoding genes of Echinococcus and Taenia crassiceps

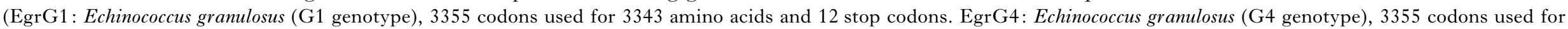

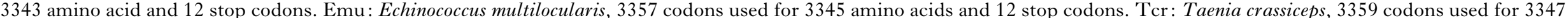

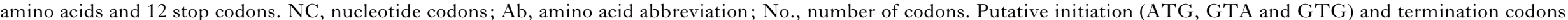
(TAA and TAG) are underlined.)

\begin{tabular}{|c|c|c|c|c|c|c|c|c|c|c|c|c|c|c|c|c|c|c|c|}
\hline \multirow[b]{2}{*}{$\mathrm{NC}$} & \multirow[b]{2}{*}{$\mathrm{Ab}$} & \multicolumn{2}{|c|}{ EgrG1 } & \multicolumn{2}{|c|}{ EgrG4 } & \multicolumn{2}{|l|}{ Emu } & \multicolumn{2}{|l|}{ Tcr } & \multirow[b]{2}{*}{$\mathrm{NC}$} & \multirow[b]{2}{*}{$\mathrm{Ab}$} & \multicolumn{2}{|c|}{ EgrG1 } & \multicolumn{2}{|c|}{ EgrG4 } & \multicolumn{2}{|l|}{ Emu } & \multicolumn{2}{|l|}{ Tcr } \\
\hline & & No. & $\%$ & No. & $\%$ & No. & $\%$ & No. & $\%$ & & & No. & $\%$ & No. & $\%$ & No. & $\%$ & No. & $\%$ \\
\hline TTT & Phe & 378 & $11 \cdot 2$ & 393 & $11 \cdot 7$ & 404 & $12 \cdot 0$ & 412 & $12 \cdot 3$ & TAT & Tyr & 205 & $6 \cdot 1$ & 201 & $6 \cdot 0$ & 193 & $5 \cdot 7$ & 199 & 5.9 \\
\hline ТTC & Phe & 20 & $0 \cdot 6$ & 14 & $0 \cdot 4$ & 14 & $0 \cdot 4$ & 20 & $0 \cdot 6$ & TAC & Tyr & 11 & $0 \cdot 3$ & 14 & $0 \cdot 4$ & 19 & $0 \cdot 6$ & 18 & $0 \cdot 5$ \\
\hline TTA & Leu & 145 & $4 \cdot 3$ & 158 & $4 \cdot 7$ & 181 & $5 \cdot 4$ & 314 & $9 \cdot 3$ & TAA & * & 4 & $0 \cdot 1$ & 6 & $0 \cdot 2$ & 4 & $0 \cdot 1$ & 4 & $0 \cdot 1$ \\
\hline TTG & Leu & 304 & $9 \cdot 0$ & 292 & $8 \cdot 7$ & 272 & $8 \cdot 1$ & 154 & $4 \cdot 6$ & $\underline{\mathrm{TAG}}$ & * & 8 & $0 \cdot 2$ & 6 & $0 \cdot 2$ & 8 & $0 \cdot 2$ & 8 & $0 \cdot 2$ \\
\hline C'T'T & Leu & 32 & $1 \cdot 0$ & 24 & $0 \cdot 7$ & 24 & $0 \cdot 7$ & 24 & $0 \cdot 7$ & CAT & His & 46 & $1 \cdot 4$ & 49 & $1 \cdot 5$ & 46 & $1 \cdot 4$ & 51 & $1 \cdot 5$ \\
\hline СТC & Leu & 2 & $0 \cdot 1$ & 1 & $<0 \cdot 1$ & - & $0 \cdot 0$ & - & $0 \cdot 0$ & CAC & His & 4 & $0 \cdot 1$ & 3 & $0 \cdot 1$ & 3 & $0 \cdot 1$ & 1 & $<0 \cdot 1$ \\
\hline C'TA & Leu & 8 & $0 \cdot 2$ & 12 & $0 \cdot 4$ & 7 & $0 \cdot 2$ & 15 & $0 \cdot 4$ & CAA & Gln & 8 & $0 \cdot 2$ & 7 & $0 \cdot 2$ & 10 & $0 \cdot 3$ & 13 & $0 \cdot 4$ \\
\hline CTG & Leu & 15 & $0 \cdot 4$ & 12 & $0 \cdot 4$ & 14 & $0 \cdot 4$ & 7 & $0 \cdot 2$ & $\mathrm{CAG}$ & Gln & 17 & $0 \cdot 5$ & 18 & $0 \cdot 5$ & 14 & $0 \cdot 4$ & 8 & $0 \cdot 2$ \\
\hline ATT & Ile & 140 & $4 \cdot 2$ & 136 & $4 \cdot 1$ & 149 & $4 \cdot 4$ & 174 & $5 \cdot 2$ & $\mathrm{AAT}$ & Asn & 77 & $2 \cdot 3$ & 83 & $2 \cdot 5$ & 87 & $2 \cdot 6$ & 89 & $2 \cdot 6$ \\
\hline ATC & Ile & 9 & $0 \cdot 3$ & 10 & $0 \cdot 3$ & 5 & $0 \cdot 1$ & 2 & $0 \cdot 1$ & $\mathrm{AAC}$ & Asn & 4 & $0 \cdot 1$ & 4 & $0 \cdot 1$ & 1 & $<0 \cdot 1$ & 5 & $0 \cdot 1$ \\
\hline ATA & Ile & 50 & $1 \cdot 5$ & 61 & $1 \cdot 8$ & 67 & $2 \cdot 0$ & 126 & $3 \cdot 7$ & AAA & Asn & 16 & $0 \cdot 5$ & 13 & $0 \cdot 4$ & 18 & $0 \cdot 5$ & 59 & $1 \cdot 8$ \\
\hline$\underline{\mathrm{ATG}}$ & Met & 90 & $2 \cdot 7$ & 96 & $2 \cdot 9$ & 91 & $2 \cdot 7$ & 99 & $2 \cdot 9$ & $\mathrm{AAG}$ & Lys & 42 & $1 \cdot 2$ & 44 & $1 \cdot 3$ & 43 & $1 \cdot 3$ & 49 & 1.5 \\
\hline GTT & Val & 267 & $7 \cdot 9$ & 255 & $7 \cdot 6$ & 240 & $7 \cdot 1$ & 183 & $5 \cdot 4$ & GAT & Asp & 78 & $2 \cdot 3$ & 79 & $2 \cdot 4$ & 74 & $2 \cdot 2$ & 81 & $2 \cdot 4$ \\
\hline GTC & Val & 12 & $0 \cdot 4$ & 7 & $0 \cdot 2$ & 9 & $0 \cdot 3$ & 3 & $0 \cdot 1$ & GAC & Asp & 2 & $0 \cdot 1$ & 3 & $0 \cdot 1$ & 2 & $0 \cdot 1$ & 3 & $0 \cdot 1$ \\
\hline GTA & Val & 47 & $1 \cdot 4$ & 65 & 1.9 & 75 & $2 \cdot 2$ & 75 & $2 \cdot 2$ & GAA & Glu & 17 & $0 \cdot 5$ & 20 & $0 \cdot 6$ & 17 & $0 \cdot 5$ & 31 & 0.9 \\
\hline$\overline{\mathrm{GTG}}$ & Val & 139 & $4 \cdot 1$ & 131 & 3.9 & 112 & $3 \cdot 3$ & 67 & $2 \cdot 0$ & GAG & Glu & 48 & $1 \cdot 4$ & 46 & $1 \cdot 4$ & 46 & $1 \cdot 4$ & 26 & $0 \cdot 8$ \\
\hline TC'T & Ser & 98 & $2 \cdot 9$ & 96 & $2 \cdot 9$ & 99 & $2 \cdot 9$ & 123 & $3 \cdot 7$ & TG'T & Cys & 140 & $4 \cdot 2$ & 129 & $3 \cdot 8$ & 144 & $4 \cdot 3$ & 126 & $3 \cdot 7$ \\
\hline TCC & Ser & 6 & $0 \cdot 2$ & 3 & $0 \cdot 1$ & 2 & $0 \cdot 1$ & 2 & $0 \cdot 1$ & TGC & Cys & 9 & $0 \cdot 3$ & 11 & $0 \cdot 3$ & 4 & $0 \cdot 1$ & 9 & $0 \cdot 3$ \\
\hline TCA & Ser & 20 & $0 \cdot 6$ & 23 & $0 \cdot 7$ & 36 & $1 \cdot 1$ & 40 & $1 \cdot 2$ & TGA & $\operatorname{Trp}$ & 29 & $0 \cdot 9$ & 37 & $1 \cdot 1$ & 33 & $1 \cdot 0$ & 51 & $1 \cdot 5$ \\
\hline TCG & Ser & 36 & $1 \cdot 1$ & 30 & $0 \cdot 9$ & 21 & $0 \cdot 6$ & 15 & $0 \cdot 4$ & TGG & Trp & 66 & $2 \cdot 0$ & 60 & $1 \cdot 8$ & 58 & $1 \cdot 7$ & 35 & $1 \cdot 0$ \\
\hline CCT & Pro & 36 & $1 \cdot 1$ & 45 & $1 \cdot 3$ & 45 & $1 \cdot 3$ & 48 & $1 \cdot 4$ & CGT & Arg & 35 & $1 \cdot 0$ & 34 & $1 \cdot 0$ & 34 & $1 \cdot 0$ & 42 & $1 \cdot 2$ \\
\hline $\mathrm{CCC}$ & Pro & 2 & $0 \cdot 1$ & 2 & $0 \cdot 1$ & - & $0 \cdot 0$ & 1 & $<0 \cdot 1$ & CGC & Arg & 2 & $0 \cdot 1$ & 4 & $0 \cdot 1$ & 1 & $<0 \cdot 1$ & 1 & $<0 \cdot 1$ \\
\hline $\mathrm{CCA}$ & Pro & 14 & $0 \cdot 4$ & 9 & $0 \cdot 3$ & 13 & $0 \cdot 4$ & 16 & 0.5 & CGA & Arg & 1 & $<0 \cdot 1$ & 3 & $0 \cdot 1$ & 7 & $0 \cdot 2$ & 2 & $0 \cdot 1$ \\
\hline $\mathrm{CCG}$ & Pro & 17 & $0 \cdot 5$ & 15 & $0 \cdot 4$ & 13 & $0 \cdot 4$ & 7 & $0 \cdot 2$ & CGG & Arg & 12 & 0.4 & 12 & $0 \cdot 4$ & 9 & $0 \cdot 3$ & 3 & $0 \cdot 1$ \\
\hline $\mathrm{ACT}$ & Thr & 60 & $1 \cdot 8$ & 68 & $2 \cdot 0$ & 65 & $1 \cdot 9$ & 70 & $2 \cdot 1$ & AGT & Ser & 93 & $2 \cdot 8$ & 107 & $3 \cdot 2$ & 113 & $3 \cdot 4$ & 104 & $3 \cdot 1$ \\
\hline $\mathrm{ACC}$ & Thr & 2 & $0 \cdot 1$ & 1 & $<0 \cdot 1$ & - & $0 \cdot 0$ & - & $0 \cdot 0$ & AGC & Ser & 9 & $0 \cdot 3$ & 6 & $0 \cdot 2$ & 7 & $0 \cdot 2$ & 1 & $<0 \cdot 1$ \\
\hline $\mathrm{ACA}$ & Thr & 8 & $0 \cdot 2$ & 2 & $0 \cdot 1$ & 9 & $0 \cdot 3$ & 14 & $0 \cdot 4$ & AGA & Ser & 25 & $0 \cdot 7$ & 30 & $0 \cdot 9$ & 31 & $0 \cdot 9$ & 43 & $1 \cdot 3$ \\
\hline $\mathrm{ACG}$ & Thr & 19 & $0 \cdot 6$ & 20 & $0 \cdot 6$ & 14 & $0 \cdot 4$ & 8 & $0 \cdot 2$ & $\mathrm{AGG}$ & Ser & 49 & $1 \cdot 5$ & 38 & $1 \cdot 1$ & 33 & $1 \cdot 0$ & 29 & $0 \cdot 9$ \\
\hline GCT & Ala & 48 & $1 \cdot 4$ & 52 & $1 \cdot 5$ & 59 & $1 \cdot 8$ & 50 & $1 \cdot 5$ & GGT & Gly & 146 & $4 \cdot 4$ & 140 & $4 \cdot 2$ & 155 & $4 \cdot 6$ & 111 & $3 \cdot 3$ \\
\hline $\mathrm{GCC}$ & Ala & 9 & $0 \cdot 3$ & 4 & $0 \cdot 1$ & 4 & $0 \cdot 1$ & - & $0 \cdot 0$ & GGC & Gly & 12 & $0 \cdot 4$ & 10 & $0 \cdot 3$ & 5 & $0 \cdot 1$ & 7 & $0 \cdot 2$ \\
\hline $\mathrm{GCA}$ & Ala & 7 & $0 \cdot 2$ & 8 & $0 \cdot 2$ & 8 & $0 \cdot 2$ & 6 & $0 \cdot 2$ & GGA & Gly & 22 & $0 \cdot 7$ & 22 & $0 \cdot 7$ & 21 & $0 \cdot 6$ & 33 & $1 \cdot 0$ \\
\hline GCG & Ala & 16 & $0 \cdot 5$ & 15 & $0 \cdot 4$ & 11 & $0 \cdot 3$ & 6 & $0 \cdot 2$ & GGG & Gly & 62 & $1 \cdot 8$ & 56 & $1 \cdot 7$ & 54 & $1 \cdot 6$ & 35 & $1 \cdot 0$ \\
\hline
\end{tabular}




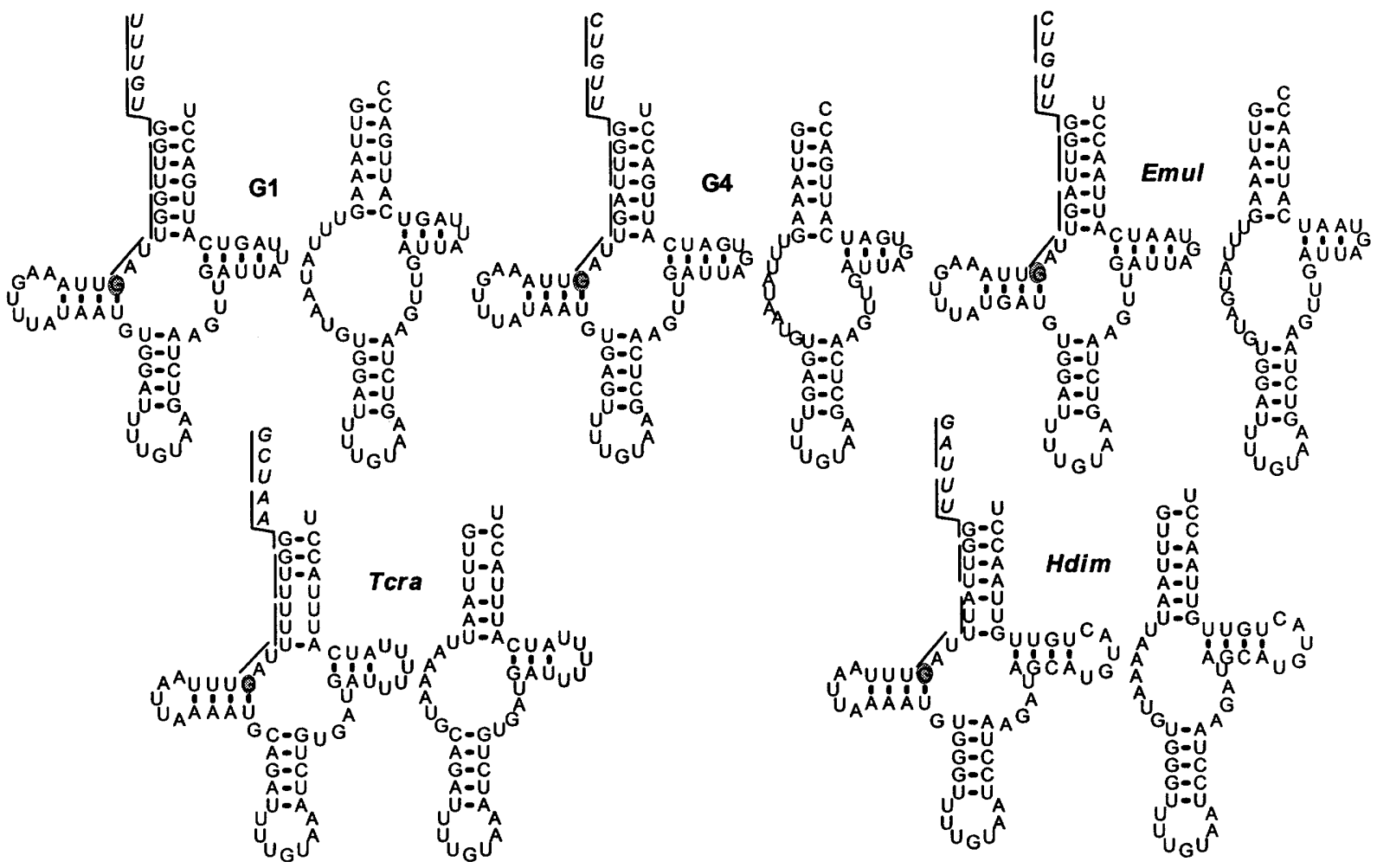

Fig. 2. Alternative structures for tRNA(T) in Echinococcus granulosus genotypes G1 and G4 (indicated as G1 and G4 in figure), E. multilocularis (Emul), Taenia crassiceps (Tcra) and Hymenolepis diminuta (Hdim). See text for details. The left-hand drawing of each pair shows the tRNA(T) structure with a paired DHU arm. If cox1 is terminated with the codon TAG, then there is a $10 \mathrm{nt}$ overlap between $\operatorname{cox} 1$ and $t r n T$. The reading frame of the overlapping sequence tract is indicated by vertical (or diagonal) lines and the $5 \mathrm{nt}$ in $\operatorname{cox} 1$ preceding $\mathrm{tRNA}(\mathrm{T})$ are shown in italics (with $\mathrm{T}$ shown as $\mathrm{U}$ for consistency). The right-hand drawing of each pair shows the alternative structure for tRNA(T) lacking a paired DHU arm. In each case, this structure starts with the nucleotide $(\mathrm{G})$ at the end of the putative TAG stop codon for $\operatorname{cox} 1$. Thus, there needs be no overlap between $\operatorname{cox} 1$ and $\operatorname{trn} T$ if the TAG stop codon is abbreviated to $\mathrm{T}$ or TA, or at most a $1 \mathrm{nt}$ overlap if the full stop codon is used.

\section{MATERIALS AND METHODS}

\section{Parasite materials and determination of $m t D N A$} sequence

Echinococcus granulosus G1 (sheep strain) and G4 (horse strain) genotypes were of United Kingdom origin, G6 (camel strain) was obtained from Kenya, G7 (pig strain) was obtained from Poland and the G8 (cervid strain) was of Alaskan origin. E. vogeli was obtained from South America and E. oligarthrus was from Panama. Techniques for genomic DNA extraction from starting materials (protoscoleces in all cases) and PCR application for obtaining the $\mathrm{mt}$ fragments have been described (Le, Blair \& McManus 2001 a). The Taenia crassiceps (American strain: Zarlenga \& George, 1995) mtDNA molecule was sequenced from available $\mathrm{mt}$ clones in combination with PCR (see Le et al. 2000). The complete mtDNA sequences for genotypes 1 and 4 of $E$. granulosus were also obtained using PCR strategies (Le et al. 2001). In brief, a combination of 'long PCR' and conventional PCR amplified overlapping fragments spanning the $\mathrm{mt}$ genome. Some PCR products were sequenced directly while others were cloned. Primer-walking was used to obtain overlapping sequences on both strands. Sequencing of PCR fragments and/or recombinant plasmid DNA was performed on an automated sequencer (ABI 377, Applied Biosystems) using specific or M13 universal sequencing primers. Both strands were completely sequenced and at least 6 sequences (3 from each strand) were aligned to obtain the final sequence for characterization. PCR was also used to amplify and subsequently sequence the atp6 gene from the E. granulosus genotypes G1, G4, G6, G7, G8, E. vogeli and E. oligarthrus and the nad3 gene from all these taxa except $E$. oligarthrus.

\section{Sequence analysis}

Sequences were aligned using AssemblyLIGN v $1.9 \mathrm{c}$ and analysed using the MacVector 6.5.3 package (Oxford Molecular Group). Preliminary identity of a sequence or a region was assigned by comparison with corresponding platyhelminth sequences obtained by us (Le et al. 2000; Le, Blair \& McManus, $2000 b)$ or available in the GenBank database (http://www.ncbi.nlm.nih.gov/Web/Genbank) using BLAST searches. Protein-encoding genes were 
identified by sequence similarity of translated open reading frames to $\mathrm{mt}$ gene sequences available in the GenBank database. The platyhelminth $\mathrm{mt}$ genetic code (Garey \& Wolstenholme, 1989; Telford et al. 2000; Nakao et al. 2000) was used for translation as done previously for a number of platyhelminth species (Le et al. 2000). The possibility of unusual initiation and termination codons (Wolstenholme, 1992) was considered when characterizing proteinencoding genes. In the case of the small, poorly conserved genes (nad3, nad4L, nad6), hydrophilicity profiles, drawn in MacVector 6.5.3, were additionally used to confirm identity.

The identities of the ribosomal RNA sequences were established based on their similarity with those found in other parasitic platyhelminthes (Le et al. $2000 a, b, 2001)$ and by their potential to form rRNAlike secondary structures. Ends of rRNA genes were not determined experimentally: consequently, these genes were assumed to consist of the entire sequence tract lying between flanking genes. Most of the transfer RNAs were identified by preliminary screening with tRNAscan-SE (Lowe \& Eddy, 1997) with parameters specified for mitochondrial/chloroplast DNA using the invertebrate $\mathrm{mt}$ genetic code for tRNA prediction (available at http://www.genetics. wustl.edu/eddy/tRNAscan-SE/). Remaining tRNA genes were identified by inspection of the sequences, taking into account both sequence similarity to homologues from other species and ability to form the appropriate secondary structure. All secondary structures were drawn using RNAViz (De Rijk \& De Wachter, 1997). Throughout, we have used the convention for abbreviating names of $\mathrm{mt}$ genes and their products as used by von Nickisch-Rosenegk et al. (2001).

The extent of genetic divergence among the detected $\mathrm{mt}$ genotypes was estimated by pairwise comparisons of nucleotide and inferred amino acid sequences. These were aligned by eye and submitted to MEGA2 (Kumar et al. 2001) for phylogenetic analysis. Pairwise distances among nucleotide sequences were calculated using the Kimura 2parameter method to compensate for multiple substitutions. Distances among inferred amino acid sequences were calculated using a Poisson correction for multiple hits. Trees were constructed using the minimum evolution approach. Taenia crassiceps was used as the outgroup for rooting trees. Bootstrap resampling was used to gain an indication of the level of support for internal branches.

\section{RESULTS AND DISCUSSION}

\section{Gene organization and content}

The complete mt sequences for Echinococcus granulosus G1 genotype (EgrG1) (13588 bp, GenBank Accession number AF297617), E. granulosus G4 genotype (EgrG4) (13598 bp, GenBank Accession 
Table 4. Amino acid codon usage of the mitochondrial protein-encoding genes

(AA : abbreviation of amino acid codons as 3 letters; Ab: as 1 letter. No.; number of codons. Tcr; Taenia crassiceps; Emu; Echinococcus multilocularis; Egr; E. granulosus (G1; genotype 1; G4; genotype 4).)

\begin{tabular}{|c|c|c|c|c|c|c|c|c|c|c|c|c|c|c|c|c|c|c|c|}
\hline \multirow[b]{2}{*}{ AA } & \multirow[b]{2}{*}{$\mathrm{Ab}$} & \multicolumn{2}{|l|}{ Tcr } & \multicolumn{2}{|c|}{ Emu } & \multicolumn{2}{|c|}{ EgrGl } & \multicolumn{2}{|c|}{ EgrG4 } & \multirow[b]{2}{*}{ AA } & \multirow[b]{2}{*}{$\mathrm{Ab}$} & \multicolumn{2}{|l|}{ Tcr } & \multicolumn{2}{|c|}{ Emu } & \multicolumn{2}{|c|}{ EgrGl } & \multicolumn{2}{|c|}{ EgrG4 } \\
\hline & & No. & $\%$ & No. & $\%$ & No. & $\%$ & No. & $\%$ & & & No. & $\%$ & No. & $\%$ & No. & $\%$ & No. & $\%$ \\
\hline Ala & $\mathrm{A}$ & 62 & $1 \cdot 9$ & 82 & $2 \cdot 4$ & 80 & $2 \cdot 4$ & 79 & $2 \cdot 4$ & Met & M & 100 & $3 \cdot 0$ & 91 & $2 \cdot 7$ & 90 & $2 \cdot 7$ & 96 & 2.9 \\
\hline Cys & $\mathrm{C}$ & 135 & $4 \cdot 0$ & 148 & $4 \cdot 4$ & 149 & $4 \cdot 4$ & 140 & $4 \cdot 2$ & Asn & $\mathrm{N}$ & 153 & $4 \cdot 6$ & 106 & $3 \cdot 2$ & 97 & $2 \cdot 9$ & 100 & $3 \cdot 0$ \\
\hline Asp & $\mathrm{D}$ & 84 & $2 \cdot 5$ & 76 & $2 \cdot 3$ & 80 & $2 \cdot 4$ & 82 & $2 \cdot 5$ & Pro & $\mathrm{P}$ & 72 & $2 \cdot 1$ & 71 & $2 \cdot 1$ & 69 & $2 \cdot 1$ & 71 & $2 \cdot 1$ \\
\hline Glu & $\mathrm{E}$ & 57 & $1 \cdot 7$ & 63 & 1.9 & 65 & $1 \cdot 9$ & 66 & $2 \cdot 0$ & Gln & $\mathrm{Q}$ & 21 & $0 \cdot 6$ & 24 & $0 \cdot 7$ & 25 & $0 \cdot 7$ & 25 & 0.7 \\
\hline Phe & $\mathrm{F}$ & 431 & $12 \cdot 9$ & 418 & $12 \cdot 5$ & 398 & $11 \cdot 9$ & 407 & $12 \cdot 2$ & Arg & $\mathrm{R}$ & 48 & $1 \cdot 4$ & 51 & $1 \cdot 5$ & 50 & $1 \cdot 5$ & 53 & $1 \cdot 6$ \\
\hline Gly & G & 186 & $5 \cdot 5$ & 235 & $7 \cdot 0$ & 242 & $7 \cdot 2$ & 228 & $6 \cdot 8$ & Ser & $\mathrm{S}$ & 357 & $10 \cdot 7$ & 342 & $10 \cdot 3$ & 336 & $10 \cdot 1$ & 333 & $10 \cdot 0$ \\
\hline His & $\mathrm{H}$ & 52 & $1 \cdot 6$ & 49 & $1 \cdot 5$ & 50 & $1 \cdot 5$ & 52 & $1 \cdot 6$ & Thr & $\mathrm{T}$ & 92 & $2 \cdot 8$ & 88 & $2 \cdot 6$ & 89 & $2 \cdot 7$ & 91 & $2 \cdot 7$ \\
\hline Ile & I & 302 & $9 \cdot 0$ & 221 & $6 \cdot 6$ & 199 & 5.9 & 207 & $6 \cdot 2$ & Val & $\mathrm{V}$ & 329 & $9 \cdot 8$ & 436 & $13 \cdot 1$ & 465 & $13 \cdot 9$ & 458 & $13 \cdot 7$ \\
\hline Lys & $\mathrm{K}$ & 49 & $1 \cdot 5$ & 43 & $1 \cdot 3$ & 42 & $1 \cdot 3$ & 44 & $1 \cdot 3$ & $\operatorname{Trp}$ & W & 86 & $2 \cdot 6$ & 91 & $2 \cdot 8$ & 95 & $2 \cdot 9$ & 97 & 2.9 \\
\hline Leu & $\mathrm{L}$ & 514 & $15 \cdot 3$ & 498 & $14 \cdot 9$ & 506 & $15 \cdot 1$ & 499 & $14 \cdot 9$ & Tyr & $\mathrm{Y}$ & 217 & $6 \cdot 5$ & 212 & $6 \cdot 3$ & 216 & $6 \cdot 4$ & 215 & $6 \cdot 4$ \\
\hline
\end{tabular}

number AF346403), and T. crassiceps (13503 bp, GenBank Accession number AF216699) were determined. The genomes are relatively small with that of $T$. crassiceps being the smallest known among metazoans (Wolstenholme, 1992; Boore, 1999; Le et al. 2000). The coding portions $(97 \cdot 4-98 \cdot 6 \%$ of the total $\mathrm{mt}$ genome) and the protein-encoding portions (around $74 \%$ ) are similar in length in all species and genotypes. Individual genes are very similar in length among the cestode species. The positions, lengths, and other features of genes and non-coding sequences for $E$. granulosus G1 genotype and $T$. crassiceps are compared with E. multilocularis (Nakao et al. 2001) in Table 1. The complete sequence for the E. granulosus G1 genotype is presented semischematically in Fig. 1.

All the 36 genes typically found in helminth $\mathrm{mt}$ genomes (12 protein-, 22 tRNA- and 2 rRNAencoding genes) have been identified and are transcribed in the same direction (Fig. 1). As is the case with other helminths (Okimoto et al. 1992; Keddie, Higazi \& Unnasch, 1998; Le et al. 2000; Le, Blair \& McManus $2000 a, b, 2001$; von Nickisch-Rosenegk et al. 2001) atp 8 is absent. The gene arrangement is basically identical in all cestode species (although in $H$. diminuta, the adjacent $t r n S_{2(U C N)}$ and $t r n L_{1(C U N)}$ have exchanged places relative to the situation in taeniids - see von Nickisch-Rosenegk et al. 2001) and is similar to that found in trematodes (except $S$. mansoni, see Le et al. 2000, 2001b). Genes abut one another or are separated by short intergenic sequences. However, each genome has 2 somewhat longer non-coding regions: one (designated NR1) sited between $\operatorname{trn} Y$ and $\operatorname{trn} L_{1(C U N)}$, and the other (designated NR2) located downstream of nad5. The lengths of NR2 are similar among all the cestodes. In the case of NR1, however, that of E. multilocularis is 3 times the length seen in any of the other cestodes and accounts for the overall larger $\mathrm{mt}$ genome size of this species.
Some pairs of adjacent genes overlap in the $\mathrm{mt}$ genomes of the cestodes reported here: (i) there is an overlap of $40 \mathrm{nt}$ (including the stop codon of nad $4 \mathrm{~L}$ ) between nad $4 L$ and nad4 in a different reading frame, a phenomenon seen in all sequenced parasitic platyhelminths, with the exceptions of $S$. mansoni (overlap only $28 \mathrm{nt}$ : Le et al. 2000, 2001) and $H$. diminuta (overlap of $16 \mathrm{nt}$ : von Nickisch-Rosenegk et al. 2001); (ii) a $1 \mathrm{nt}$ overlap (T) occurs between $\operatorname{trn} Q$ and $\operatorname{trnF}$ in all Echinococcus species and genotypes, but not in $T$. crassiceps; (iii) a 4 nt overlap is present in all cestode species between $\operatorname{trnF}$ and $\operatorname{trn} M$; (iv) depending on interpretation, an overlap of up to $10 \mathrm{nt}$ occurs between the $3^{\prime}$ end of cox 1 and $\operatorname{trn} T$ in all cestodes (discussed further below); (v) $2 \mathrm{nt}(\mathrm{AG})$ at the $5^{\prime}$ end of $\operatorname{trn} S_{1(A G N)}$ are shared with the termination TAG codon of $n a d 3$ in the G1 and G4 genotypes of E. granulosus and T. crassiceps, but not in E. multilocularis; (vi) in T. crassiceps, the stop codon of cob overlaps by $1 \mathrm{nt}$ with nad $4 L$ and a similar situation occurs for atp6 and nad2. In the cases listed in (v) and (vi) it is possible that the stop codon of the upstream gene is in fact abbreviated (to TA or T), as has been noted in a number of mitochondrial genomes (see Wolstenholme, 1992; Le et al. 2001; Le, Blair \& McManus, 2001).

\section{Initiation and termination codons}

In almost all cases, ATG or GTG initiate, and TAA or TAG terminate translation of protein-encoding genes among the taeniid cestodes (Table 1). However, the same start and stop codons are not always used in all homologous genes among the different species (Table 1). For example, GTG acts as an initiation codon in nad1 of E. granulosus G1 genotype whereas ATG performs the same function in the G4 genotype, T. crassiceps and E. multilocularis. The $E$. granulosus G4 genotype utilizes the stop codons TAA and TAG equally (Table 2), unlike the 


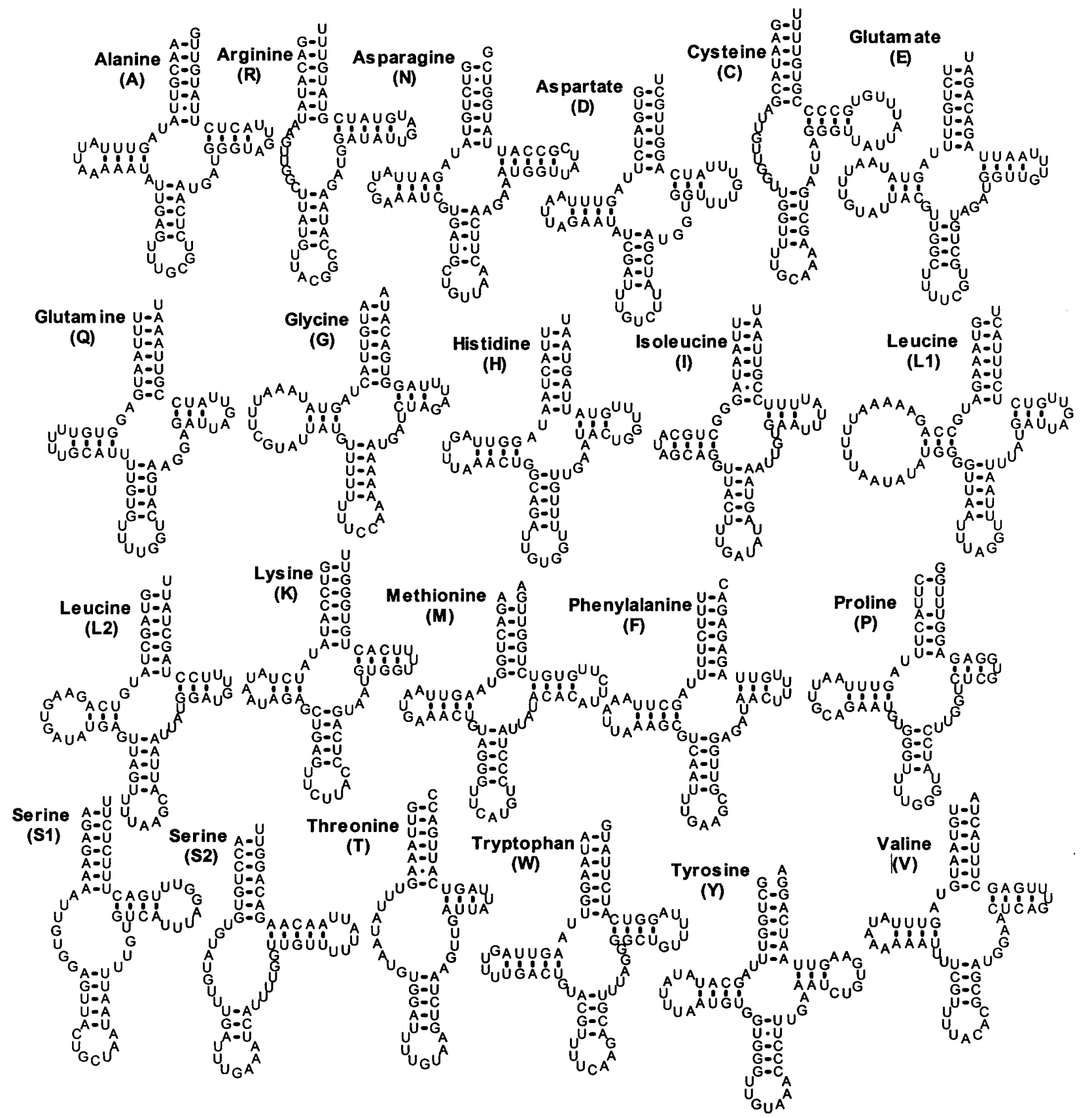

Fig. 3. Secondary structure models for the 22 tRNAs of Echinococcus granulosus G1 genotype. See text for details.

The structure shown for $\mathrm{tRNA}(\mathrm{T})$ is the form lacking the DHU arm.

situation in other taxa in which TAA is less common.

Resolution of initiation and termination codons in cox 1 has proved to be difficult. In all 4 taeniid species or genotypes, a typical initiation codon (ATG) is found near the start of $\operatorname{cox} 1$. We would regard this as the true start codon, except for the fact that there is a 2-nt deletion just downstream of it in the G4 genotype of E. granulosus, thus changing the reading frame for this taxon. A more likely start codon for the Echinococcus species/genotypes is therefore GTG/GTA located 9 codons downstream from the ATG codon. This position aligns with the codon (GTT) chosen by von Nickisch-Rosenegk et al. (2001) as the initiator of transcription in $\operatorname{cox} 1$ of $H$. diminuta. The codon TTG found at this position in
T. crassiceps could be a start codon. However, there is an in-frame ATG located 3 codons upstream of this which might be the true start codon in that species.

In their analysis of the mt genome of $H$. diminuta, von Nickisch-Rosenegk et al. (2001) inferred that cox 1 terminated with an abbreviated stop codon ('T) and thus did not overlap the downstream $\operatorname{trn} T$. They also pointed out that an in-frame stop codon ( $\mathrm{TAG}$ ) occurred downstream of the abbreviated codon, implying a $10 \mathrm{nt}$ overlap with $\operatorname{trn} T$ if this were the true stop codon. We have examined this region in our sequences from taeniids. For each of the cestode species, it is possible to construct alternative structures for $\mathrm{tRNA}(\mathrm{T})$, one with a paired DHU arm and 


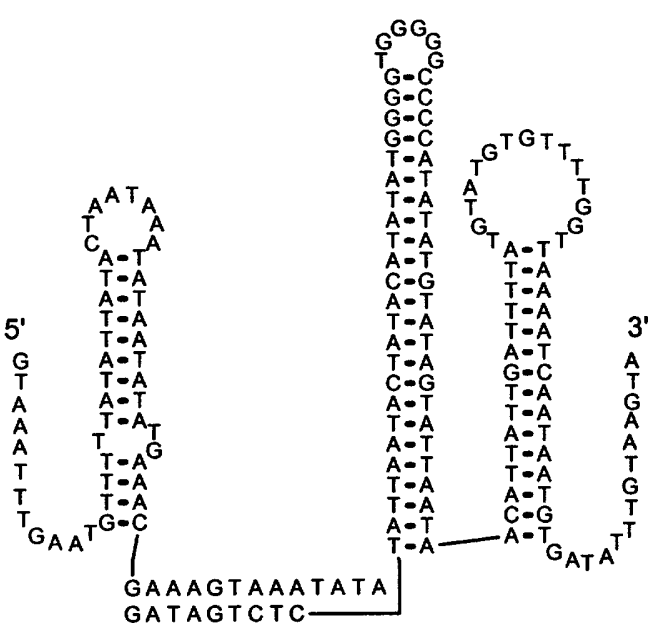

Fig. 4. Putative secondary structure for the NR2 (noncoding region 2) of Echinococcus granulosus G1 genotype.

one lacking this arm (Fig. 2). Structures lacking the DHU arm overlap by only $1 \mathrm{nt}(\mathrm{G})$ with the TAG codon mentioned above. Abbreviation of such a codon to $\mathrm{T}$ or TA remains a possibility. Structures possessing the DHU arm, such as the structure figured by von Nickisch-Rosenegk et al. (2001), overlap cox 1 by $10 \mathrm{nt}$, assuming that TAG is the stop codon. Von Nickisch-Rosenegk et al. (2001) suggested that the codon TTG, the last nt of which overlaps the structure possessing the DHU arm, might be abbreviated to $\mathrm{T}$ and act as a stop codon, thus eliminating any overlap with the downstream $\operatorname{trnT}$. Codons in the same position as this TTG in other cestode taxa do not always start with $\mathrm{T}$ (Fig. 2 -only E. multilocularis and E. granulosus G4 genotype have such codons) and therefore could not act as abbreviated stop codons. We think it likely that the true stop codon for cox 1 is the TAG (or TA) mentioned above. However, we are undecided as to which structure for $\mathrm{tRNA}(\mathrm{T})$ is to be preferred and consequently we are uncertain as to the extent of overlap between $\operatorname{cox} 1$ and $\operatorname{trn} T$.

\section{Nucleotide and amino acid composition}

The $\mathrm{A}+\mathrm{T}$ content of the complete $\mathrm{mt}$ genomes differ slightly among the Echinococcus species and genotypes $(67 \cdot 0-69 \cdot 1 \%)$ on the one hand and $T$. crassiceps $(74 \%)$ on the other (Table 3 ). There is very low use of $\mathrm{C}(\sim 8 \%)$ in all species, but the use of $\mathrm{A}$ and $\mathrm{G}$ differs; lower $\mathrm{A}(\sim 20 \%)$ and higher $\mathrm{G}$ (24-25\%) occur in Echinococcus compared with $T$. crassiceps (Table 3). These values are consistent throughout the protein and ribosomal coding sequences (Table 3). The amino acid compositions of the protein-encoding mtDNA sequences are shown in Table 4. Phe (11.9-12.9\%), Leu (14.9-15.3\%), Ser $(10 \cdot 0-10 \cdot 7 \%)$, and Val $(9 \cdot 8-13 \cdot 7 \%)$ are the most used, making up $\sim 50 \%$ of the total number, and Gln $(0 \cdot 6-0.7 \%)$, His $(1.5-1.6 \%)$, Lys $(1.3-1.5 \%)$ and $\operatorname{Arg}(\sim 1 \cdot 5)$ are the least frequently used. This correlates with the high $\mathrm{T}$ and low $\mathrm{C}$ composition of the genes and the correspondingly frequent use of $\mathrm{T}$ in codons.

\section{Transfer RNAs}

The complement of 22 tRNA-encoding genes in each of the cestode $\mathrm{mt}$ genomes presented here is typical of that found in other metazoans. As an example, predicted structures of tRNAs in the mtDNA of E. granulosus (G1 genotype) are presented in Fig. 3. Uncertainties about the structure for tRNA(T) have been discussed above and alternatives shown in Fig. 2. Lengths of tRNAs (ranging from 54-73 nt) are similar between genes of the 4 cestodes, but these sizes are less conserved between the genera Echinococcus and Taenia. The most different in length is $\operatorname{trn} L_{1(C U N)}(73 \mathrm{nt}$ in both Echinococcus species but only $65 \mathrm{nt}$ in T. crassiceps) (Table 1). As in other parasitic platyhelminths and a number of other metazoans, both the tRNAs specific for serine lack a DHU arm (Fig. 3). The trnR and $\operatorname{trn} C$ genes, in all species, have a DHU replacement loop, a feature never $(\operatorname{trn} R)$ or sometimes $(\operatorname{trn} C)$ observed in trematodes (see Le et al. 2001). There is an unusually large loop closing the DHU arm in the trn $L_{1(C U N)}$ gene structure of E. granulosus (Fig. 3) and E. multilocularis.

\section{Non-coding sequences}

Apart from short intergenic sequences ranging from 1 to $39 \mathrm{nt}$ (the longest in all 4 taeniid taxa being that between $\operatorname{trn} L_{1(C U N)}$ and $\operatorname{trn} S_{2(U C N)}$,), there are 2 other intergenic or non-coding regions (NR) which are functionally unassigned (Table 1 ). One, designated NR1, lies between $\operatorname{trn} Y$ and $\operatorname{trn} L_{1(C U N)}$ and is much shorter in the E. granulosus genotypes (66 nt) than in E. multilocularis $(183 \mathrm{nt})$ but very similar in length and sequence to NR1 in T. crassiceps (65 nt). NRl in $T$. crassiceps, with the inclusion of a few bases at the $3^{\prime}$ end of the $\operatorname{trn} Y$, forms a stem of $23 \mathrm{bp}$ with a capping loop of $7 \mathrm{nt}$ (von Nickisch-Rosenegk et al. 2001). Despite a degree of sequence similarity with T. crassiceps, the NR1 of E. granulosus G1 and G4 genotypes can form only a much shorter stem of $7 \mathrm{bp}$ or fewer, and the inclusion of the $3^{\prime}$ end of $\operatorname{trn} Y$ does not lead to formation of a longer stem. Similarly, the initial $65 \mathrm{nt}$ of the E. multilocularis NR1, which has some sequence similarity with the NR1 in other taeniids, cannot fold on itself to form long stem-loop structures. However, the complete NR1 in $E$. multilocularis $(183 \mathrm{nt}$ ) has the potential to form long stems (von Nickisch-Rosenegk et al. 2001). It is noteworthy that among the 4 taeniid species/ genotypes discussed here, E. multilocularis stands out in possessing a long NR1 with a strong secondary structure. 


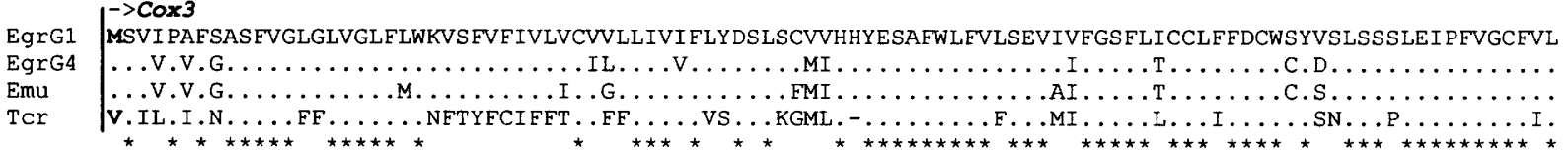

EgrG1 LGSSITVTGFHHLLGWRCCDLLLFMTIVLGLSFVVLQILEMEEVSCNIVDGSFYSSSFCTVGLHFSHVVLGVIGLVTLFLVGSDNFGVYRCTVLAWYWHF

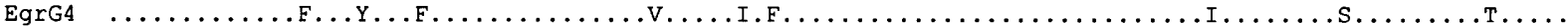

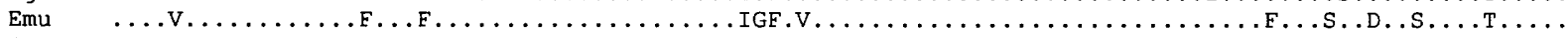

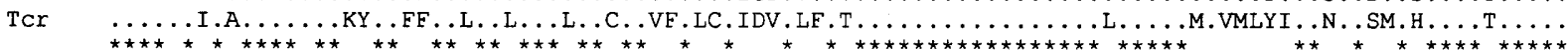
->COb EgrG1 VDYIWLLVYTVVYVCXMIVLFRRNLIDLPINYSLNYYWSSGFVLSVFMILQIVTGVLLSEVYVADFMCSFFMVMNLSNDSFFTWCLRYWHMVGVNVLFIL

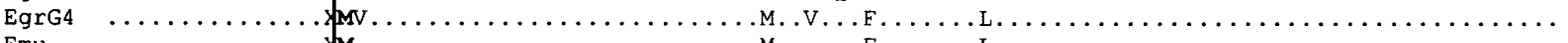

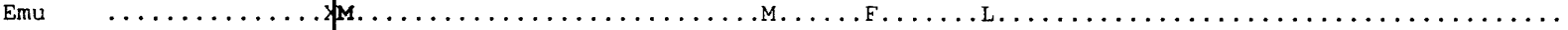

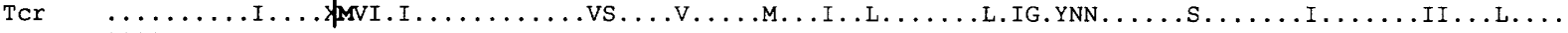

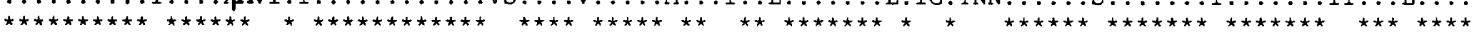

EgrG1 EgrG4 Emu $\mathrm{TCr}$

EgrG EgrG4

Emu

TCr

EgrG1 EgrG Emu

TCr

EgrG]

EgrG4

Emu

TCr

EgrG EgrG4

Emu

$\mathrm{TCr}$

EgrG

EgrG4

Emu

TCr

EgrG1

EgrG4

Emu

Tcr

EgrG1 EgrG

Emu

Tcr

EgrG1 EgrG4 Emu

TCr

EgrG1 EgrG4 Emu TCr

LFFHMGMALYYGSYVKKGVWNVGFI LYLLVMGEAFTGY I LPWHOMSYWAATVLTSI IDSL PVVGSIVYKYVVGGFSVSGDTLIRIFSVH ICLGFVI IGLM

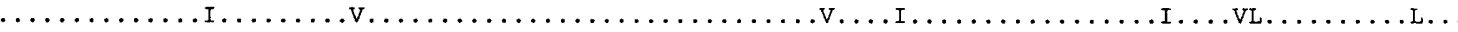

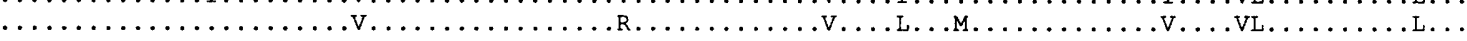

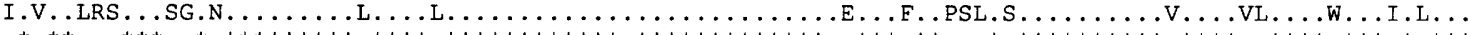

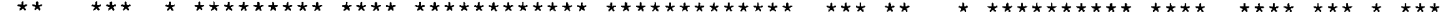

IVHLFYLHKDGNSNPLFSFYSFNDLVYFHSYFTVKDLVLFLVTCSLVVFWLFEVPDLLVDIESYLEADYLNT PVSIKPEWYFLAFYAI LRCINSKVGGLL

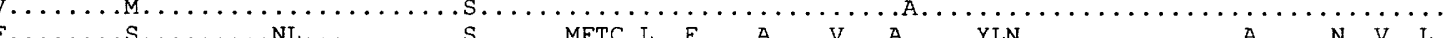

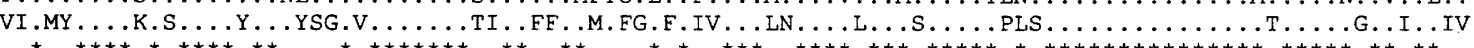
->Nad4L

LIMSEI FFLWI PTEGGSSVYSVWRQVNFWLIVSLFLSLTYLGGCHPEY PYLMVCQLFSLMMVLMMLVEKLYX--VVTLFLLFSFVIMVSYFLTVGRFLNS

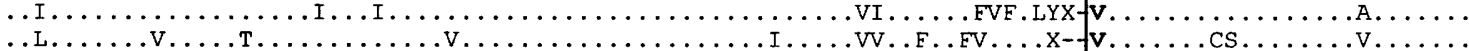

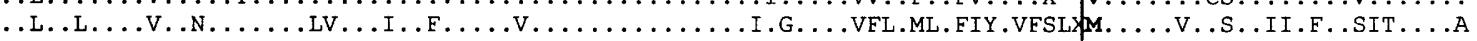

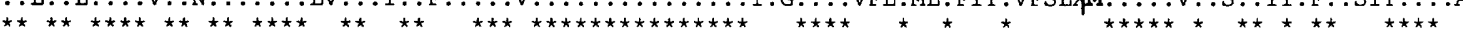
$>$ Nad4

LIILENFNVLVLLFCLLFSSLDNHMI FITLMVISTLEI I ISLTVLTRVWECSSCLELVDF XMSVFFLFGVGWFLIVSVVLLFSLLYSCGVGCCWLVCDKV

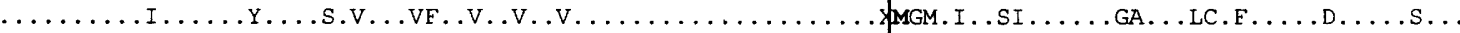

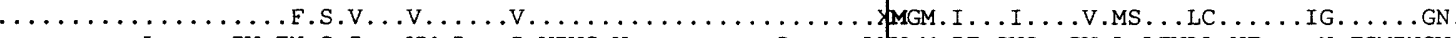

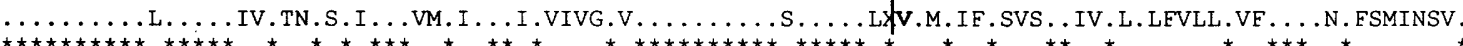

CNSLFVFDSASFYLVVLVLI LGLYSQVMFFGLLTIQVRFFLSVSMVFAILCFCINHSIFFWCVYELSMFPLLYLIFSESPYSERFLASWYFSGYLLSTSL

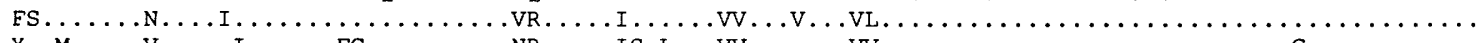

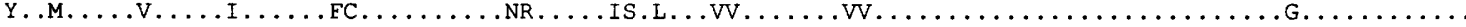

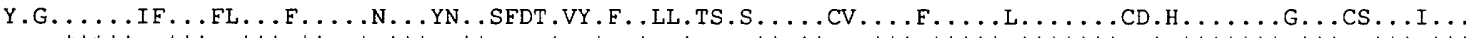

PLILILLYLSYVNGSFFFSEWCYGGDVSLSI FYVLSFVFFTKVPLVPFHTWLPIVHAEATSVVSI FLSGY IMKLGLLGVYRSTFFI LDLSFVGYLSICCL

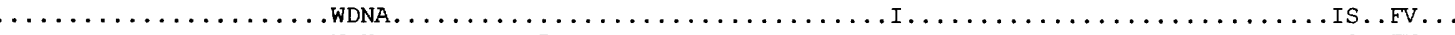

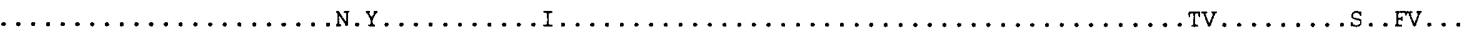

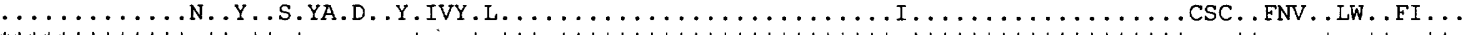

VAIGFLVTACSELDGKRWLAFLSLSHIVVPFLGFFVSDWISVGYSFFYCLGHGLSAAIVFGLLWCFYDVSNTRNWVLLKSGVGGVVSMVIVVLSMLSLCS

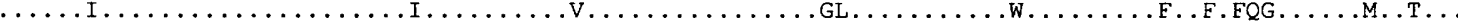

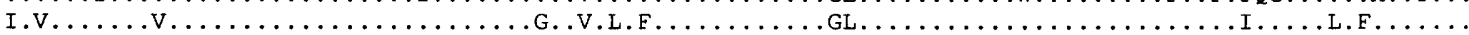

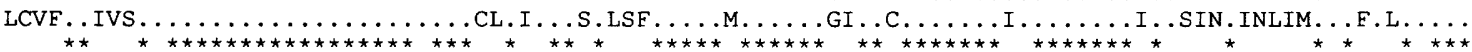

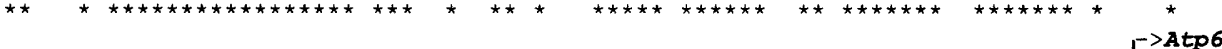

FPTTVQFFCEVYLVVQCSGVLLYLLFWVCYLFFGGLVPLVLCGYLLIRSEYYEFVCVSYHCYYFFLCYLGVWCYFAIVVL גWVVNDFCSLIGLVYMLVF

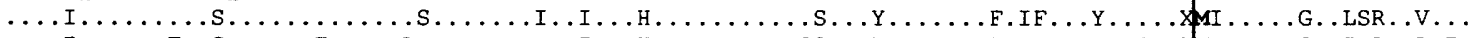

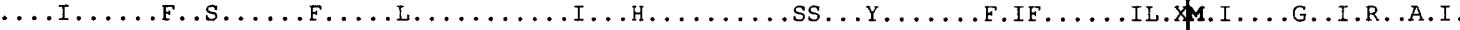

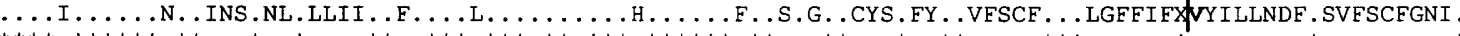

GR-VSYYYFVLLALVLMWFMVYRLPYCYSVYLFSVFLFCVVFVMFVSLFMCRI FNNVNGFFACFVPLGTPLWICFLVCLAESISYVIRPVVLVLRPFINI

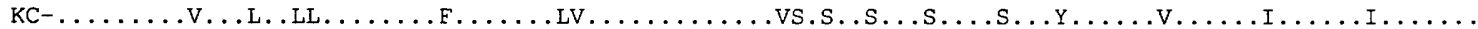

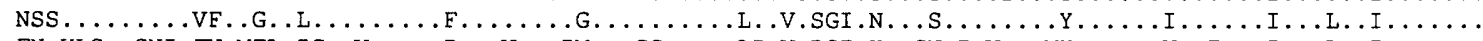

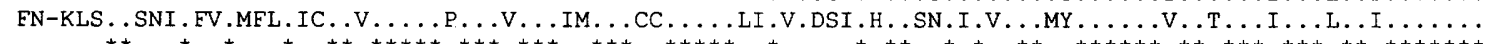
SLGCFGAVALGNLCFVNCWWGLVLVGLFFYEVFVVLI HWY IVSSILDESVDH $\$$ PFVRVFFY FDVVVFSFVFSMLFCFLCCVVDSLFGFWVFLELCGLAIVP

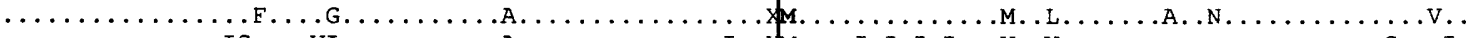

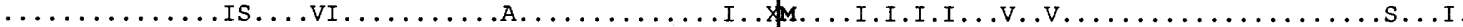

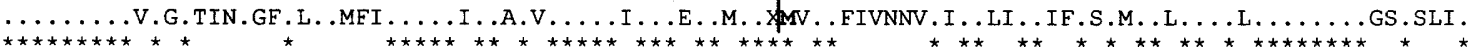

Fig. 5. For legend see p. 108.

The NR2 is more uniform in length among Echinococcus species/genotypes (184 in G1, 182 in G4 and 177 in E. multilocularis) and the sequences are similar in all cases. Von Nickisch-Rosenegk et al. (2001) have proposed a secondary structure for this region in E. multilocularis. Comparisons among the Echinococcus species/genotypes allow us to refine this slightly, and our interpretation for E. granulosus G1 genotype (there are only minor differences in the other 2 forms of Echinococcus) is shown in Fig 4. In 
EgrG1 SFFCGLGLNFYNLYSSVLSYI IMSGLSSVLLIFGLLVSSLYYFIFFGFVVKFGLFPFMLWVYRVFSVGSWVFIFLLSVVMKFPVLFFCFLYQTSGLGLVL

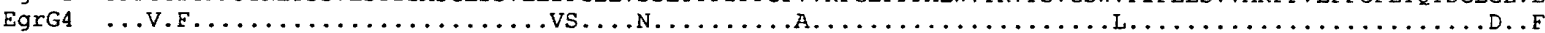

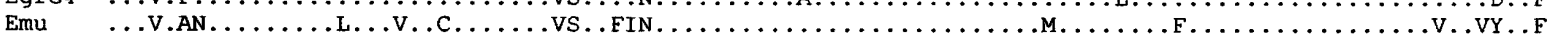

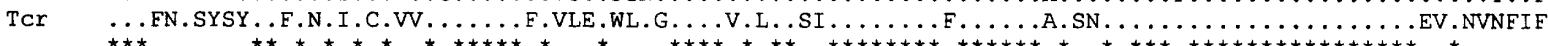

EgrG1 VDCWLSIFVCSCLVWFFSLSLEYIWCHISLSSVSTLVVACFYSETQTCFFIYWYYFFWGLCSIVYFAVVSDLTDLKGYYFWLFCFLLLVTPLSMPLIYKI

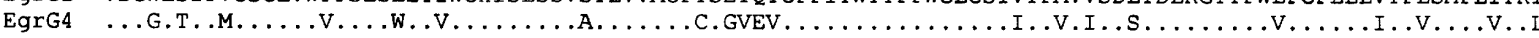

Emu $\quad \ldots$ G.T.............................GIEI.......................................

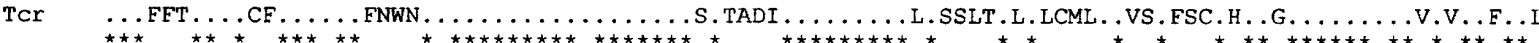
$>$ Nad1

EgrG1 SVCVGIFYSSIYILLVWVVYSFSEQFFLFKLGGDYFYSSVENCWVEXWVVFGLVSGVFGLLISLLIIAFFVLGERKVLGYSQSRKGPNKVGVIGLLQSFA

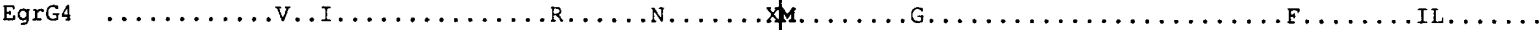

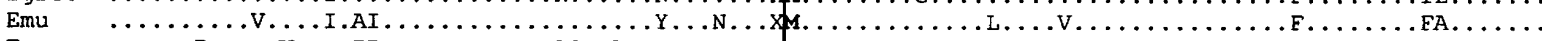

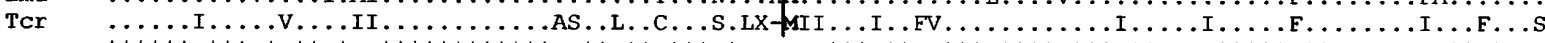

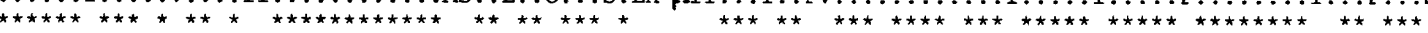

EgrG1 DLLKLVIKFKCFYFQSRSYVGLFGVVLLMALVIVYSFIYGSYYSASYSGLSVLWFLAAASTSSYSLLCTGWGGYNNYSFLSSVRCAFGSVSFEACFMCVV

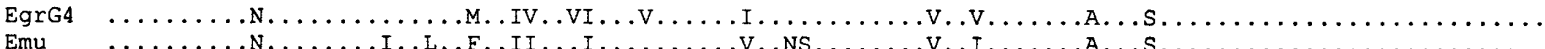

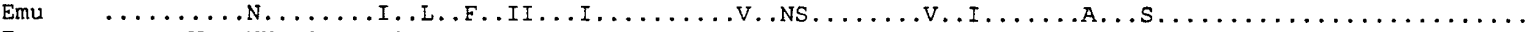

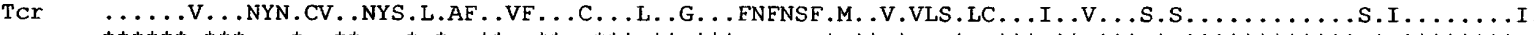

EgrG1 IFCALCSCSYNLIDFYYNCWLSLLLFPLIYVLFLICILCETNRT PFDYGEAESELVSGFNVEYSGIYFTCLFACEYIII IYVFSWLGVVLMFGGGFIGMLV

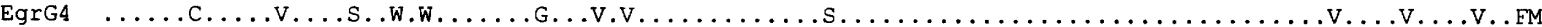

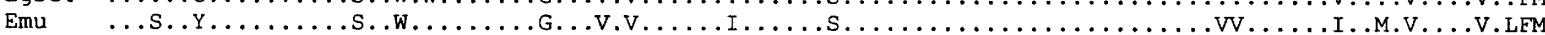

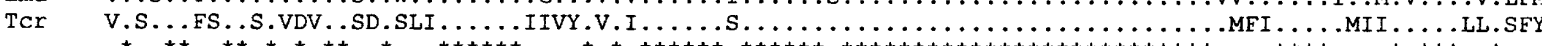

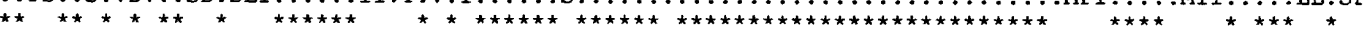

EgrG1 LVFNLLFFMWARATLPRVRYDCFVNFFWEVCLCMLILGLFAIVN $\$$ MVVLFFVFFVFFLFGFIYFFNCGLLNKYGVVGFEWGSSYECGFFSAMISLDCFS

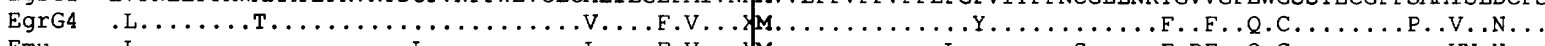

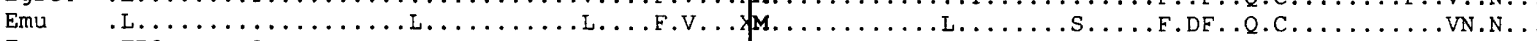

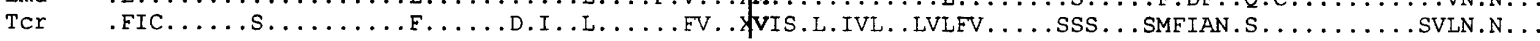

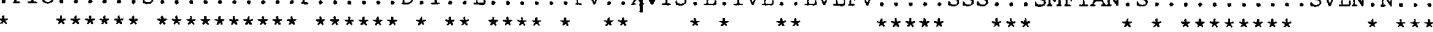
EgrGI FTYFSLLVVFVIFDLEVSLLLNMPLQGVLFGNFWCYYFFLLVMFLGFVVELFSGYVRWVY $>$ Cox 1 -VIFTLDHKRIGVIYSLLGIWSGFVGLSFSLL

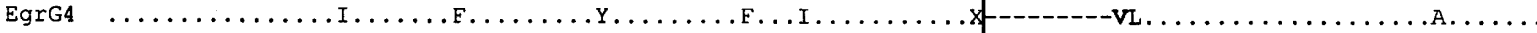

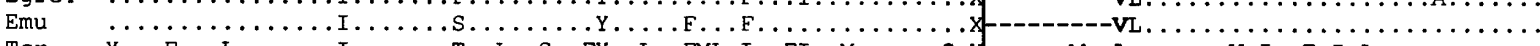

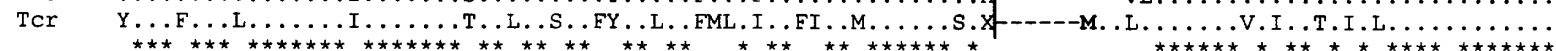

EgrG1 IRVNELEPYYNVIPLDCYNFLVTNHGIIMIFFFLMPILIGGFGNYLLPLLGGLSDLNLPRLNALSAWLLI PSLVFLLVSMCLGAGVGWTFY PPLSSSYFS

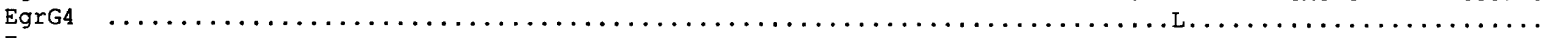

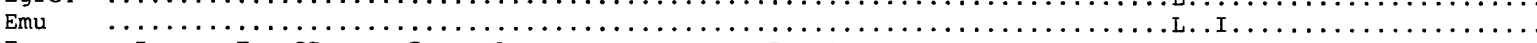

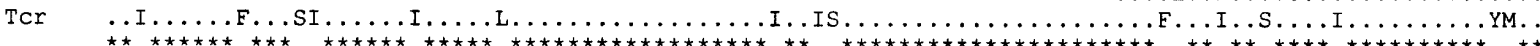

EgrG1 SSCGVDFLMFSLHLAGVSSVFSINFICTLYSVFMTNVESRTSIVLWSYLFTSVLLLVTLPVLAAAITMLLFDRNFCSAFFDPLGGGDPILFQHMFWFFG

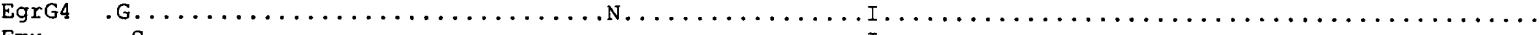

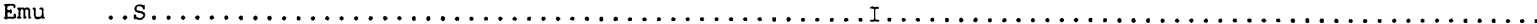

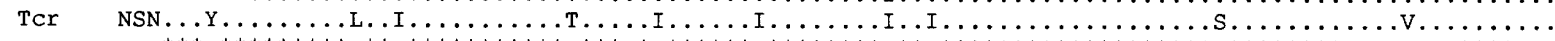

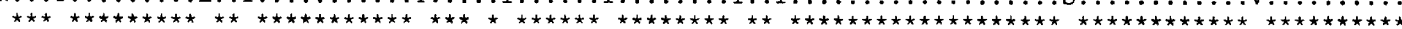

EgrG1 HPEVYVLILPGFGI ISHICLSISANFDAFGFYGLLFAMFSIVCLGSSVWGHHMFTVGLDVKTAVFFSSVTMI IGVPTGIKVFTWLYMLLNSSVNVSDPVL EgrG4 Emu HEEVYVLILPGEGISHTCLSISANFDAFGEYGLLFAMFSIVCLGSSVWGHHMFTVGLDVKIAVFFSSVTMIIGVPTGIKVFTWLYMLLNSSVWVDPVL

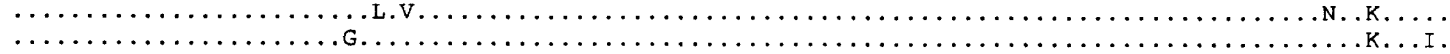

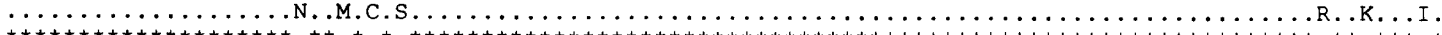

EgrG1 WWVVSFIVLFTEGGVTGIVLSACVLDNI LHDTWFVVAHFHYVMSLGSY ISI IVMFIWWWPLITGLSLNKCLLQCQCI I SNVGFNLCFFPMHYFGLCGLPR EgrG4 Emu

Ter

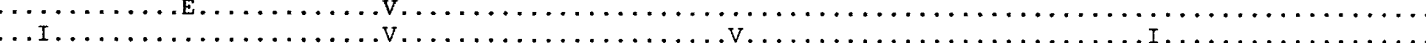

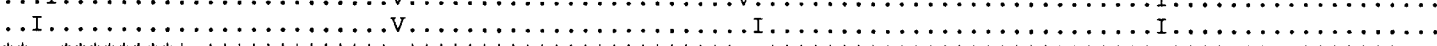

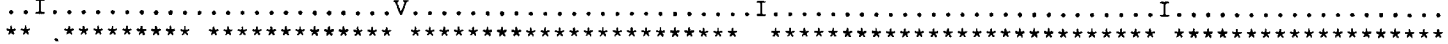

EgrG1 RVCIYEYSYNWINVVCTVGSFISAFSGCFFVFILWESIVSKNEVLGSYNSS-GLVDCLMSPVACHNDYFCYPYSVDYTYGVYYMRWDDCTYAFVVGX-VV

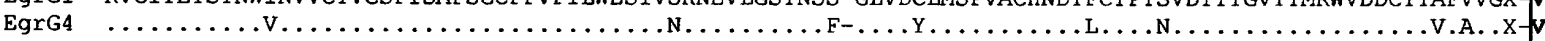

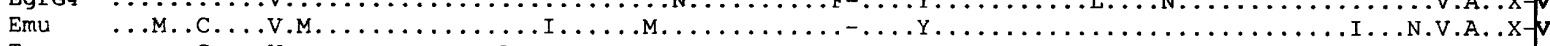

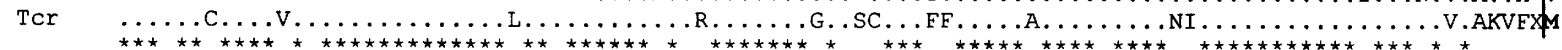

EgrG1 NLSLLYYDIVCYIVAVCVFIVCFVYVLLCWNVVFGVGTVNFGSENQIIELVWTVIPTVVVLLCALNVNFITSDLDCFSSETIKVVGHQWYWTYEYFGGG

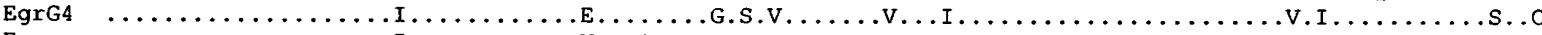

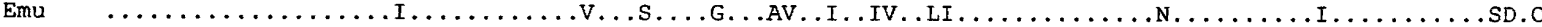

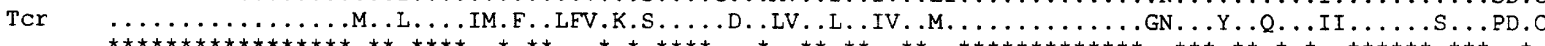

Fig. 5. For legend see p. 108.

contrast with NR1, the NR2 of $T$. crassiceps is very different from those of the Echinococcus species in sequence and in secondary structure (as proposed by von Nickisch-Rosenegk et al. 2001) as well as being slightly longer (194 nt).
Mitochondrial sequence variation in Echinococcus and $\mathrm{E}$. granulosus genotypes

Now that complete $m$ t genomes are available for 2 genotypes of E. granulosus, for E. multilocularis and 


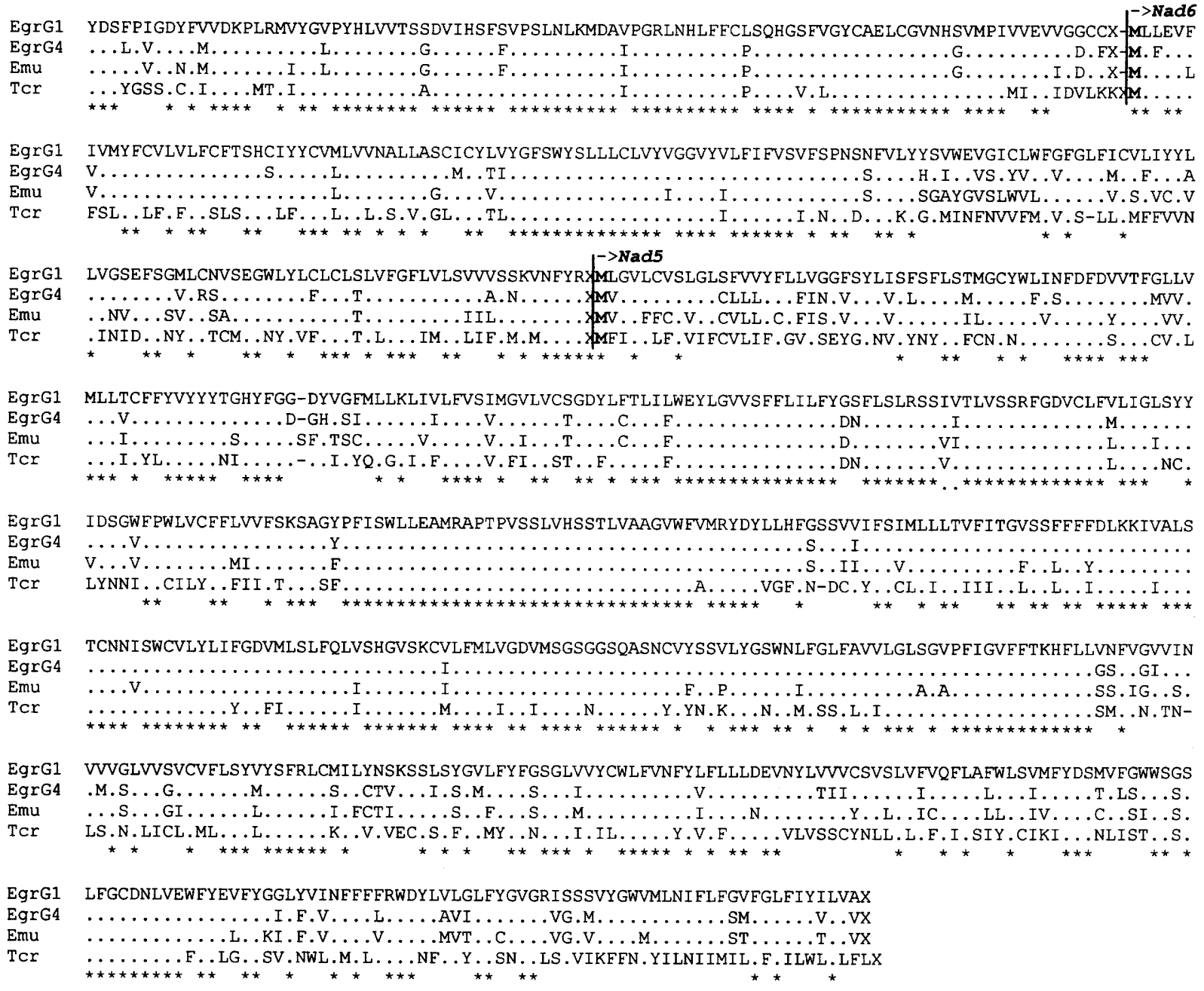

Fig. 5. An alignment of amino acid sequences of the $12 \mathrm{nt}$ protein-encoding genes of Echinococcus granulosus genotypes 1 (EgrG1) and 4 (EgrG4), E. multilocularis (Emu) and Taenia crassiceps (Tcr). Termination codons are marked with the letter X. Dots (.) indicate residues identical with those in EgrG1. Sites conserved in all taxa are indicated by an asterisk (*) under the alignment. Amino acids for the initiation codons (either M or V) are shown in bold to mark the start position of the proteins. See text concerning the start codon for $\operatorname{cox} 1$.

for an additional taeniid ( $T$. crassiceps), we are in a position to use these data to (i) make a preliminary statement as to which mt genes are the most variable and therefore likely to be useful at shallow phylogenetic depths (e.g. at the level of species or genotype) and (ii) measure the divergence between genotypes of $E$. granulosus relative to other taeniids.

A useful first step in assessing variability of genes is to inspect alignments of different genes. Fig. 5 shows an alignment of all 12 protein sequences from the 4 taxa. Differences are most noticeable among proteins such as Cox3, Nad4L, Atp6, Nad3, Cox2 and Nad6 that are generally less conserved in $\mathrm{mt}$ genomes. Some proteins, such as Nad5, have tracts that are highly conserved and tracts that are very variable. Cox 1 is the most conserved protein among these species, as has been observed in other parasitic platyhelminths (Le et al. 2001; Le, Blair \& McManus, 2001). The assumption that $\operatorname{cox} 1$ is therefore a good candidate gene for the study of deep phylogenies needs to be tested. Morgan \& Blair (1998) found that, despite its apparent conservatism, the $\operatorname{cox} 1$ gene in trematodes had only a relatively few sites free to vary and consequently became saturated with substitutions even at shallow phylogenetic depths.

For 2 of the variable genes, atp6 and nad3, we obtained sequences from additional taxa: E. granulosus genotypes 1, 4, 6, 7, 8 (EgrG1, EgrG4, EgrG6, EgrG7 and EgrG8), E. multilocularis, E. vogeli, E. oligarthrus (not nad3) and $T$. crassiceps. The percentage pairwise comparison of nucleotide and amino acid composition for nad3 is shown in Table $5 \mathrm{~A}$ and for atp6 is presented in Table 5B. The nucleotide divergence is less than amino acid divergence in all cases, implying that there are few synonymous substitutions. Of the 348 nucleotide positions in the nad3 alignment, 40 (11.5\%) were variable among the Echinococcus species and genotypes and $103(29.6 \%)$ were variable when com- 
Table 5. Percentage pairwise divergences of nucleotides (above diagonal) and amino acids (below diagonal) of the nad3 gene (A) and atp6 gene (B) for genotypes G1, G4, G6, G7, G8 of Echinococcus granulosus, E. multilocularis, E. vogeli, E. oligarthrus (B only) and Taenia crassiceps

(Egr; Echinococcus granulosus (genotypes 1, 4, 6, 7, 8 designated as G1, G4, G6, G7, and G8, respectively), Emu; E. multilocularis, Evo; E. vogeli, Eol; E. oligarthrus and Tcr; Taenia crassiceps.)

A

\begin{tabular}{|c|c|c|c|c|c|c|c|c|c|}
\hline & EgrG1 & EgrG4 & EgrG6 & EgrG7 & EgrG8 & $\mathrm{Emu}$ & Evo & Tcr & \\
\hline EgrG1 & - & $7 \cdot 5$ & $7 \cdot 8$ & $7 \cdot 8$ & $8 \cdot 1$ & $10 \cdot 6$ & $10 \cdot 9$ & $28 \cdot 5$ & \\
\hline EgrG4 & $11 \cdot 3$ & - & $8 \cdot 3$ & $8 \cdot 3$ & $8 \cdot 6$ & $11 \cdot 2$ & $11 \cdot 5$ & $29 \cdot 0$ & \\
\hline EgrG6 & $11 \cdot 3$ & $12 \cdot 2$ & - & $0 \cdot 0$ & $2 \cdot 0$ & $7 \cdot 8$ & 8.6 & $29 \cdot 6$ & \\
\hline EgrG7 & $11 \cdot 3$ & $12 \cdot 2$ & $0 \cdot 0$ & - & $2 \cdot 0$ & $7 \cdot 8$ & $8 \cdot 6$ & $29 \cdot 6$ & \\
\hline EgrG8 & $12 \cdot 2$ & $13 \cdot 0$ & $6 \cdot 1$ & $6 \cdot 1$ & - & $8 \cdot 6$ & $9 \cdot 5$ & $29 \cdot 0$ & \\
\hline Emu & $13 \cdot 0$ & $13 \cdot 9$ & $11 \cdot 3$ & $11 \cdot 3$ & $12 \cdot 2$ & - & $10 \cdot 6$ & $29 \cdot 0$ & \\
\hline Evo & $15 \cdot 7$ & $16 \cdot 5$ & $13 \cdot 9$ & 13.9 & 13.9 & 13.9 & - & $29 \cdot 3$ & \\
\hline Tcr & $39 \cdot 1$ & $40 \cdot 0$ & $40 \cdot 0$ & $40 \cdot 0$ & $40 \cdot 0$ & 33.9 & $34 \cdot 5$ & - & \\
\hline \multicolumn{10}{|l|}{ B } \\
\hline & EgrG1 & EgrG4 & EgrG6 & EgrG7 & EgrG8 & Emu & Evo & Eol & Tcr \\
\hline EgrG1 & - & $13 \cdot 8$ & $16 \cdot 2$ & $15 \cdot 8$ & $16 \cdot 6$ & $19 \cdot 8$ & $16 \cdot 4$ & $19 \cdot 3$ & $36 \cdot 0$ \\
\hline EgrG4 & $16 \cdot 5$ & - & $13 \cdot 8$ & $13 \cdot 8$ & $15 \cdot 2$ & $17 \cdot 0$ & $14 \cdot 2$ & $17 \cdot 9$ & $34 \cdot 1$ \\
\hline EgrG6 & $19 \cdot 4$ & $15 \cdot 9$ & - & 0.6 & $4 \cdot 7$ & $17 \cdot 0$ & $16 \cdot 0$ & $16 \cdot 0$ & $32 \cdot 9$ \\
\hline EgrG7 & $18 \cdot 8$ & $15 \cdot 3$ & $1 \cdot 2$ & - & $4 \cdot 5$ & $17 \cdot 1$ & $16 \cdot 0$ & $16 \cdot 0$ & $33 \cdot 1$ \\
\hline EgrG8 & $19 \cdot 4$ & $16 \cdot 5$ & 5.9 & $4 \cdot 7$ & - & $16 \cdot 7$ & $15 \cdot 6$ & $17 \cdot 2$ & $33 \cdot 3$ \\
\hline Emu & $18 \cdot 7$ & $17 \cdot 0$ & $18 \cdot 1$ & $17 \cdot 5$ & $17 \cdot 5$ & - & $15 \cdot 1$ & $18 \cdot 2$ & $32 \cdot 4$ \\
\hline Evo & $18 \cdot 8$ & $13 \cdot 5$ & $17 \cdot 6$ & $17 \cdot 1$ & $16 \cdot 5$ & $14 \cdot 0$ & - & $16 \cdot 0$ & $33 \cdot 1$ \\
\hline Eol & $21 \cdot 2$ & $19 \cdot 4$ & $20 \cdot 6$ & $19 \cdot 4$ & $20 \cdot 0$ & $18 \cdot 1$ & $16 \cdot 5$ & - & $32 \cdot 8$ \\
\hline Tcr & $42 \cdot 4$ & $38 \cdot 2$ & $41 \cdot 3$ & $41 \cdot 3$ & $41 \cdot 3$ & $38 \cdot 2$ & $38 \cdot 4$ & $40 \cdot 7$ & - \\
\hline
\end{tabular}

Table 6. Divergence (\%) in mitochondrial protein-coding (nucleotide; above diagonal, and amino acid; below diagonal) and in nucleotide sequences of $r r n L$ (above diagonal) and $r r n S$ (below diagonal) of the cestodes reported in this study

(For length of individual protein-encoding and ribosomal-encoding sequences, see Table 1.)

\begin{tabular}{|c|c|c|c|c|c|c|c|c|}
\hline & EgrG1 & EgrG4 & Emu & Tcr & EgrG1 & EgrG4 & Emu & Tcr \\
\hline & \multicolumn{4}{|c|}{ Protein-coding sequences } & \multicolumn{4}{|c|}{$r r n L$ and $r r n S$ sequences } \\
\hline EgrG1 & & $12 \cdot 37$ & $14 \cdot 97$ & $27 \cdot 01$ & & $8 \cdot 76$ & $11 \cdot 05$ & $23 \cdot 73$ \\
\hline EgrG4 & $11 \cdot 57$ & & $13 \cdot 01$ & $26 \cdot 37$ & $8 \cdot 18$ & & $11 \cdot 24$ & $24 \cdot 47$ \\
\hline Emu & $13 \cdot 67$ & $11 \cdot 53$ & & $25 \cdot 73$ & $11 \cdot 20$ & $10 \cdot 24$ & & $25 \cdot 41$ \\
\hline Tcr & $30 \cdot 60$ & $30 \cdot 78$ & $29 \cdot 58$ & & $22 \cdot 45$ & $22 \cdot 56$ & $22 \cdot 25$ & \\
\hline
\end{tabular}

parisons with $T$. crassiceps were included (Table 5A). Levels of nucleotide variation were greater in atp6 (516 positions) than in nad3: $69(19 \cdot 8 \%$ ) variant sites among Echinococcus species and genotypes and 125 $(36 \%)$ variant sites when comparisons with $T$. crassiceps were included (Table 5B). Alignments of the predicted amino acid sequences revealed 18 $(15.7 \%)$ and $36(21.2 \%)$ differences in the nad 3 and atp6 proteins, respectively, among Echinococcus genotypes, and $46(40 \%)$ and $72(42 \cdot 4 \%)$ respectively between Echinococcus and T. crassiceps (Table $5 \mathrm{~A}, \mathrm{~B})$. The variation in nad3 was similar to that reported previously (Bowles et al. 1992, 1994; Bowles \& McManus, 1993b) for fragments of the nad1 and cox1 genes among E. granulosus genotypes and E. multilocularis. However, atp6 exhibits greater levels of variation and should be useful for discriminating taxa at shallow phylogenetic levels.

Pairwise differences among genes can give a measure of relative levels of divergence among taxa. Such a comparison, of the complete nucleotide sequences of the protein-encoding genes and of the 2 subunits of ribosomal RNA (small; $r r n S$ and large; $r r n L)$, is shown in Table 6. The E. granulosus G1 


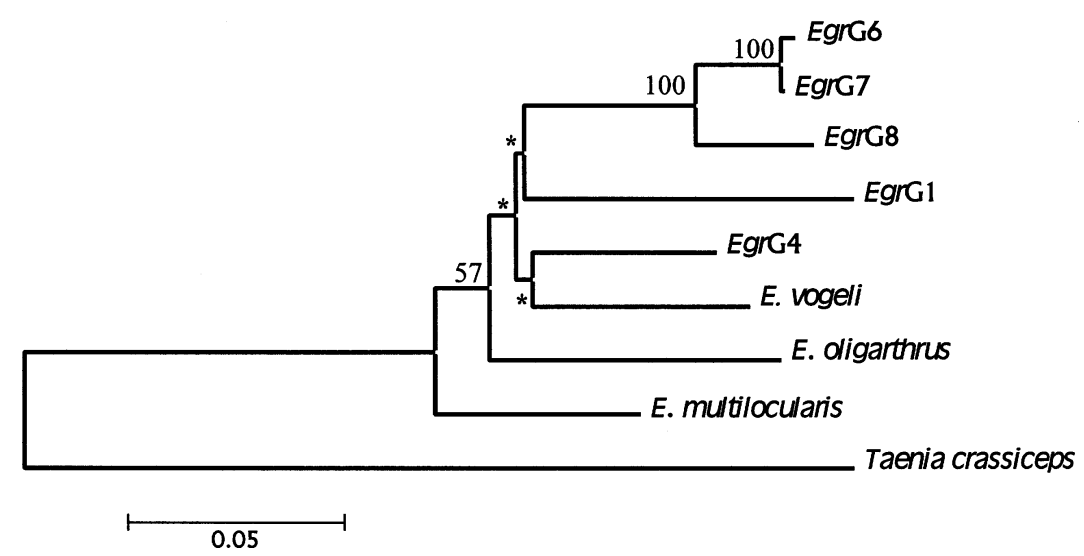

Fig. 6. Inferred relationships among species and genotypes of Echinococcus, using Taenia crassiceps as an outgroup. Concatenated sequences of atp6, nad1 (partial) and $\operatorname{cox} 1$ (partial) were analysed. A distance matrix was constructed from the inferred amino acid sequences using a Poisson correction for multiple hits and the tree constructed using the minimum evolution approach. Five hundred bootstrap resamplings were carried out. Branches with bootstrap support values less than $50 \%$ are indicated with an asterisk. EgrG1, EgrG4, EgrG6-EgrG8 are the different genotypes of $E$. granulosus. Units on scale bar: changes per site.

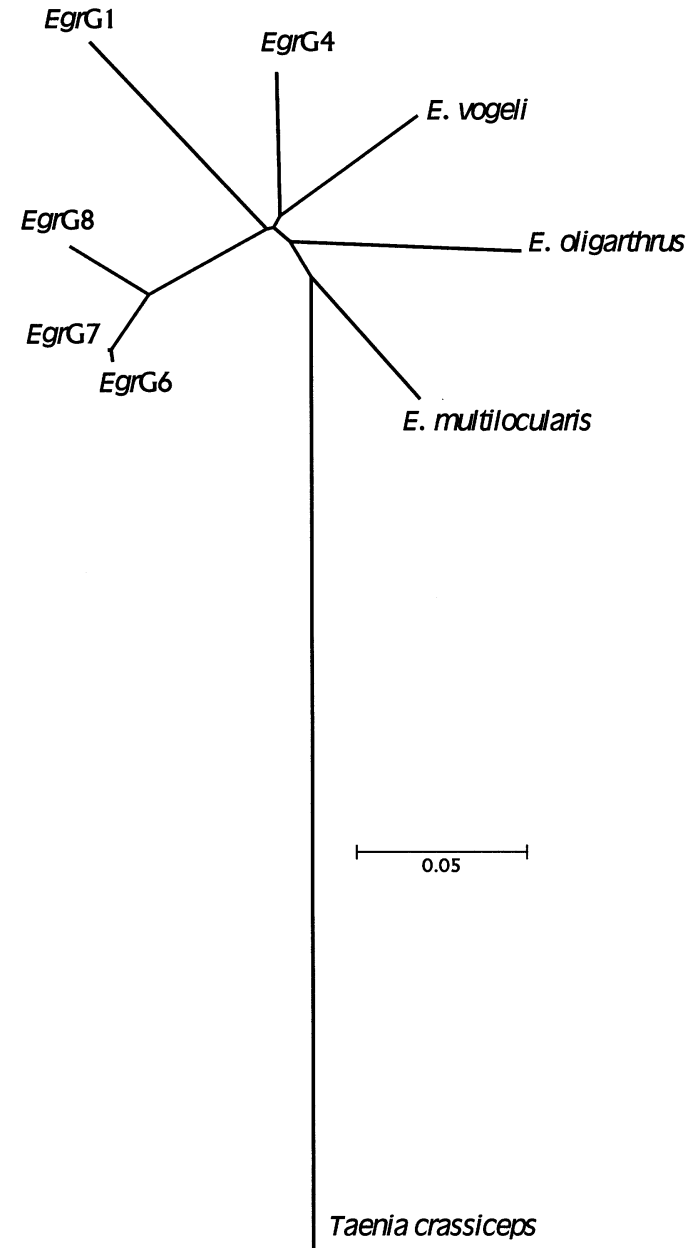

Fig. 7. Inferred relationships among species and genotypes of Echinococcus shown as an unrooted tree. Concatenated sequences of atp6, nad1 (partial) and cox 1 (partial) were analysed. A distance matrix was constructed from the nucleotide sequences using the Kimura 2-parameter correction for multiple hits and the tree constructed using the minimum evolution approach. Taxon labels as for Fig. 6. Units on scale bar: changes per site. genotype differs from the G4 genotype by $12.4 \%$ (nucleotides (nt)), and 11.6\% (amino acids (aa)), a level similar to differences between these two genotypes and E. multilocularis (13-15\% nt; and $11 \cdot 5-13 \cdot 5 \%$ aa) ('Table 6). As expected, divergence is considerably higher when any member of the genus Echinococcus is compared with $T$. crassiceps (26-30\% nt and aa differences), suggesting that saturation has not been reached within Echinococcus. In both the $r r n L$ and $r r n S$ genes, the G1 and G4 genotypes of $E$. granulosus differ by $11 \%$ from $E$. multilocularis and differ from each other by $8 \%$ (Table 6). As rRNAs are known to be conserved among related taxa, the differences between $E$. granulosus genotypes is noteworthy. The comparisons reported here suggest that EgrG1 and EgrG4 are as distinct from each other as either is from E. multilocularis.

Another approach to investigating levels of divergence is by means of phylogenetic trees. For this, we used nt sequences (complete atp6, partial nad1 (Bowles \& McManus, 1993a) and partial cox1 (Bowles et al. 1992)) for genotypes 1, 4, 6, 7, 8 (EgrG1, EgrG4, EgrG6, EgrG7 and EgrG8) of $E$. granulosus, E. multilocularis, E. vogeli, E. oligarthrus and $T$. crassiceps. The alignment was $1353 \mathrm{nt}$ (451 aa) long with 543 variable sites (168 for aa) and 262 parsimony-informative sites (67 for aa). The tree in Fig. 6 was constructed from inferred amino acid sequences. Five hundred bootstrap resamplings were conducted. T. crassiceps was chosen as the outgroup for rooting the tree. The branches indicated by an asterisk were supported by fewer than $50 \%$ of the resampled data sets and therefore should be regarded as poorly supported. The tree in Fig. 7 was constructed from nucleotide sequences and is presented without an explicit root simply to show more clearly the shortness of the internal branches separating the Echinococcus taxa. 
It is clear that EgrG4, EgrG1, E. vogeli and E. oligarthrus are almost equidistant from each other in terms of mt sequences. Furthermore, the E. granulosus G1 and G4 genotypes are also almost equidistant from the G6-8 genotype cluster, although there is some structure in this latter group. $E$. multilocularis appears as basal within the genus, but again the branch placing it there is rather poorly supported. Given this, recognition of the sheep-dog (G1 genotype) and the horse-dog (G4 genotype) strains (and possibly also the G6-8 genotypes) as separate species is appropriate. In the case of the sheep and horse strains, a wealth of other strongly supporting information (based on differences in morphological, biological, epidemiological, in vitro and in vivo developmental and biochemical features) is available (Thompson \& Lymbery, 1988; McManus \& Bryant, 1995; Thompson, 1995; Thompson \& McManus, 2001).

The horse-dog form of E. granulosus was recognized as distinct from the common sheep strain and originally promoted as a distinct subspecies, $E$. granulosus equinus, by Williams \& Sweatman (1963) based on morphological and host specificity criteria. This classification was rejected by Rausch (1967) because the horse and sheep strains exist sympatrically. However, although the two may be sympatric, their epidemiological patterns and host ranges vary and the form adapted to horses, unlike the sheep form, appears poorly or non-infective to humans (Thompson \& Smyth 1975). Despite the opinion of Rausch (1967), therefore, the discrete nature of the 2 forms is quite clear and the molecular and phylogenetic evidence from this and previous studies suggests the case for reinstatement of their formal taxonomic status as subspecies/species is now overwhelming.

This work was supported by grants from the National Health and Medical Research Council of Australia, the Australian Research Council, The Queensland Institute of Medical Research and the UNDP/World Bank/WHO Special Programme for Research and Training in Tropical Diseases (TDR).

\section{REFERENCES}

BOORE, J. L. (1999). Animal mitochondrial genomes. Nucleic Acids Research 27, 1767-1780.

Bowles, J., Blair, D. \& Mcmanus, D. P. (1992). Genetic variants within the genus Echinococcus identified by mitochondrial DNA sequencing. Molecular and Biochemical Parasitology 54, 165-173.

Bowles, J., BLAir, D. \& McManus, D. P. (1994). Molecular genetic characterization of the cervid strain ("northern form') of Echinococcus granulosus. Parasitology 109, 215-221.

BoWles, J., Blair, D. \& McManus, D. P. (1995). A molecular phylogeny of the genus Echinococcus. Parasitology 110, 317-328.
BOWLes, J. \& MCMANUS, D. P. (1993 a). Rapid discrimination of Echinococcus species and strains using a polymerase chain reaction-based RFLP method. Molecular and Biochemical Parasitology 57, 231-239.

BOWLES, J. \& MCMANUS, D. P. (1993 b). NADH dehydrogenase 1 gene sequences compared for species and strains of the genus Echinococcus. International Fournal for Parasitology 23, 969-972.

DE RIJK, P. \& DE WACHTER, R. (1997). RnaViz, a program for the visualisation of RNA secondary structure. Nucleic Acids Research 25, 4679-4684.

GAREY, J. R. \& WOLSTENHOLME, D. R. (1989).

Platyhelminth mitochondrial DNA, evidence for early evolutionary origin of a tRNA(SerAGN) that contains a dihydrouridine arm replacement loop, and of serinespecifying AGA and AGG codons. Fournal of Molecular Evolution 28, 374-387.

haAG, K. L., ZAHA, A., ARAUjia, A. M. \& GOTTSTEIN, B. (1997). Reduced genetic variability within coding and non-coding regions of the Echinococcus multilocularis genome. Parasitology 115, 521-529.

KEDDIE, E. M., HigAZI, T. \& UNNASCH, T. R. (1998). The mitochondrial genome of Onchocerca volvulus, sequence, structure and phylogenetic analysis. Molecular and Biochemical Parasitology 95, 111-127.

KUmar, s., TAMURA, K., JakobSen, I. B. \& NeI, M. (2001). MEGA2: Molecular evolutionary genetics analysis software. Bioinformatics (in the Press).

Le, T. H., Blair, D., Agatsuma, T., humair, P. F., CAMPBELl, N. J. H., IWAGAMI, M., LITTLEWOOD, D. T. J., PEACOCK, B., JOHNSTON, D. A., BARTLEY, J., ROLLINSON, D., Herniou, E. A., Zarlenga, D. S. \& McManus, D. P. (2000). Phylogenies inferred from mitochondrial gene orders - a cautionary tale from the parasitic flatworms. Molecular Biology and Evolution 17, 1123-1125.

LE, T. H., BLAIR, D. \& MCMANUS, D. P. $(2000 a)$.

Mitochondrial genomes of human helminths and their use as markers in population genetics and phylogeny. Acta Tropica 77, 243-256.

LE, T. H., Blair, D. \& Mcmanus, D. P. (2000 $b$ ).

Mitochondrial DNA sequences of human schistosomes, the current status. International Fournal for Parasitology 30, 283-290.

LE, T. H., Blair, D. \& Mcmanus, D. P. (2001). Complete DNA sequence and gene organization of the mitochondrial genome of the liver fluke, Fasciola hepatica L. (Platyhelminthes; Trematoda) Parasitology 123, 609-621.

Le, T. H., humair, P. F., Blair, D., Agatasuma, T. \& McManUs, D. P. (2001). Mitochondrial gene content, arrangement and composition compared in African and Asian schistosomes. Molecular and Biochemical Parasitology 117, 61-71.

LOWE, T. \& EDDY, S. R. (1997). tRNAscan-SE: a program improved detection of transfer RNA genes in genomic sequence. Nucleic Acids Research 25, 955-964.

MCMANUS, D. P. \& BRYANT, C. A. (1995). Biochemistry, physiology and molecular biology of Echinococcus. In The Biology of Echinococcus and Hydatid Disease (ed. Thompson, R. C. A. \& Lymbery, A. J.), pp. 135-181. CAB International, Wallingford, UK.

MORGAN, J. A. T. \& BLAIR, D. (1998). Relative merits of nuclear ribosomal internal transcribed spacers and 
mitochondrial COI and NDI genes for distinguishing among Echinostoma species (Trematoda). Parasitology 116, 289-297.

NAKAO, M., SAKo, Y., YOKOYAMA, N., FUKUnAGa, M. \& ITO, A. (2000). Mitochondrial genetic code in cestodes. Molecular and Biochemical Parasitology 11, 415-424. okimoto, R., MacFarlane, J. L., Clary, D. O. \& wolstenholme, D. R. (1992). The mitochondrial genome of two nematodes, Caenorhabditis elegans and Ascaris suum. Genetics 130, 471-498.

RAUSCH, R. L. (1967). A consideration of intraspecific categories in the genus Echinococcus Rudolphi, 1801 (Cestoda: Taeniidae). Fournal of Parasitology 53, 484-491.

RINDER, H., RAUSCH, R. L., TAKAHAShI, K., KOPP, H., THOMSCHE, A. \& LOSCHER, T. (1997). Limited range of genetic variation in Echinococcus multilocularis. Fournal of Parasitology 83, 1045-1050.

SCOTT, J. C. \& McManus, D. P. (1994). The random amplification of polymorphic DNA can discriminate species and strains of Echinococcus. Tropical Medicine and Parasitology 45, 1-4.

SCOTT, J. C., STEFAniak, J., PAWlowski, Z. S. \& McManus, D. P. (1997). Molecular genetic analysis of human cystic hydatid cases from Poland, identification of a new genotypic group (G9) of Echinococcus granulosus. Parasitology 114, 37-43.

TELFORD, M. J., HERNiOU, E. A., RUSSEll, R. B. \& LiTTLEWOOD, D. T. J. (2000). Changes in mitochondrial genetic codes as phylogenetic characters: two examples from the flatworms. Proceedings of the National Academy of Sciences, USA 97, 11359-11364. THOMPSON, R. C. A. (1995). Biology and systematics of Echinococcus. In The Biology of Echinococcus and Hydatid Disease (ed. Thompson, R. C. A. \& Lymbery, A. J.), pp. 1-50. CAB International, Wallingford, Oxon, UK.
THOMPSON, R. C. A. \& LYMBery, A. J. (1988). The nature, extent and significance of variation within the genus Echinococcus. Advances in Parasitology 27, 209-258.

Thompson, R. C. A., LyMbery, A. J. \& CONSTANTINe, C. C. (1995). Variation in Echinococcus, towards a taxonomic revision of the genus. Advances in Parasitology 35, 145-176.

THOMPSON, R. C. A. \& McManus, D. P. (2001). Aetiology: parasites and life cycles. WHO/OIE Manual on Echinococcosis in Humans and Animals (ed. Eckert, J., Gemmell, M. A., Meslin, F.-X. \& Pawlowski, Z. S.), pp. 1-19. CAB International, Wallingford, Oxon, $\mathrm{UK}$.

THOMPson, R. C. A. \& SMYTH, J. D. (1975). Equine hydatidosis: a review of the current status in Great Britain and the results of an epidemiological survey. Veterinary Parasitology 1, 107-127.

VON NICKISCH-ROSENEGK, M., BROWN, W. M. \& BOORE, J. L. (2001). Complete sequence of the mitochondrial genome of the tapeworm Hymenolepis diminuta: gene arrangements indicate that platyhelminths are eutrochozoans. Molecular Biology and Evolution 18, 721-730.

Williams, R. J. \& SWEatman, G. K. (1963). On the transmission, biology and morphology of Echinococcus granulosus equinus, a new subspecies of hydatid tapeworm in horses in Great Britain. Parasitology 53, 391-407.

WOlstenholme, D. R. (1992). Animal mitochondrial DNA, structure and evolution. International Reviews of Cytology 141, 173-216.

ZARLENGA, D. S. \& GEORGE, M. (1995). Taenia crassiceps: cloning and mapping of mitochondrial DNA and its application to the phenetic analysis of a new species of Taenia from Southeast Asia. Experimental Parasitology 81, 604-607. 